\title{
Microstructural characterisation of the Ypresian clays (Kallo-1) at nanometre resolution, using broad-ion beam milling and scanning electron microscopy
}

\section{S. Hemes ${ }^{1, *}$, G. Desbois ${ }^{1}$, J. Klaver ${ }^{1,2}$ \& J.L. Urai ${ }^{1}$}

1 Structural Geology, Tectonics and Geomechanics, Energy and Mineral Resources Group, RWTH Aachen University, Lochnerstrasse 4-20, 52062 Aachen, Germany

2 Microstructure and Porosity at Structural Geology, Tectonics and Geomechanics, Energy and Mineral Resources Group, RWTH Aachen University, Lochnerstrasse 4-20, 52062 Aachen, Germany

* Corresponding author. Email: susanne.hemes@gmx.de

Manuscript received: 13 January 2016, accepted: 18 April 2016

\section{Abstract}

Besides the Oligocene Boom Clay, the Ypresian clays - part of the Eocene Ieper Group (Kortrijk Formation and Kortemark Member) - are currently being investigated as an alternative host rock for the deep geological disposal of radioactive waste in Belgium and the Netherlands. In this study, broad-ion-beam milling and high resolution scanning electron microscopy (BIB-SEM) analyses were carried out to analyse the mineral fabrics and microstructures of representative Ypresian clay samples from different depths of the 0N-Kallo- 1 borehole (Kallo, Belgium). Qualitative microstructural observations indicate that mineral fabrics and pore morphologies in fine-grained samples are comparable to those found for fine-grained Boom Clay, but most of the Ypresian clay samples analysed also contained a significant silt fraction, which is associated with larger inter-aggregate pores, coated by a thin, very low porous clay layer. Quantitative pore-shape analysis shows lower axial ratios and elongations, as well as higher roundness and circularities for pores in the clay matrix of the more coarse-grained samples, compared to the fine-grained samples. The contribution of large pores ( $>1 \times 10^{7} \mathrm{~nm}^{2}$ pore area) to the total BIB-SEM observed porosity was found to correlate with the non-clay mineral (NCM) content of a sample. Frequencies of pore sizes within the clay matrix follow a power-law distribution, hinting towards the possibility of up-scaling of the nanometre-scale observations to larger scale (micro-) structural features of the material. Power-law exponents are comparable to values found for power-law pore-size distributions within the clay matrix of the Boom Clay, which indicates similarity of the pore-space morphologies within the clay matrix of the Boom Clay and the Ypresian clays. Wood's metal injection, followed by (cooled BIB)-SEM analysis shows that all visible pores are connected via pore throats of diameter down to $\sim 10 \mathrm{~nm}$.

Key words: BIB-SEM, microstructural analysis, nanometre-scale porosity, Wood's metal injection, Ypresian clays

\section{Introduction}

In Belgium, research on a potential host rock formation for the safe long-term disposal of high- and medium-level long-lived radioactive waste has so far been focused on the Oligocene Boom Clay. The reference location for research on the Boom Clay is the Mol-Dessel nuclear zone in the province of Antwerp (Belgium), involving the high activity disposal experimental site underground research facility (HADES-URF; Huysmans \& Dassargues, 2006; 0NDRAF/NIRAS, 2001). Since the late 1990s, the Ypresian clays - part of the Eocene Ieper Group, Kortemark Member and
Kortrijk Formation - have been considered and investigated as another potential host rock material for the deep geological disposal of radioactive waste. A research site, located in Doel, close to Antwerp (Belgium), is the reference site for methodological studies on the Ypresian clays (ONDRAF/NIRAS, 2001, 2013a). So far, mainly mineralogical and geochemical aspects of the material have been investigated, and little is known about the microstructure and mineral fabrics, in contrast to the well-documented Boom Clay (Desbois et al., 2009, 2014; Hemes et al., 2013, 2015). Information on pore-size distributions, porespace morphologies and pore-space connectivity are of special 
Table 1. XRD bulk mineralogical analysis results ( $Q_{\text {mineral }}$ Analysis and Consulting, 2014). Rietveld refinement was used for the quantification of different mineral phases and the results are given in dry wt\%.

\begin{tabular}{|c|c|c|c|c|c|c|}
\hline Mineralogy (XRD analysis) & $\begin{array}{l}\text { 0N-Kallo-1- } \\
\text { 008-a1 }\end{array}$ & $\begin{array}{l}\text { 0N-Kallo-1- } \\
020-a 1\end{array}$ & $\begin{array}{l}\text { 0N-Kallo-1- } \\
045-\mathrm{a} 1\end{array}$ & $\begin{array}{l}\text { 0N-Kallo-1- } \\
\text { 060-a1 }\end{array}$ & $\begin{array}{l}\text { 0N-Kallo-1- } \\
086-c 1\end{array}$ & $\begin{array}{l}\text { 0N-Kallo-1- } \\
\text { 108-a1 }\end{array}$ \\
\hline 2:1 clays & 28.9 & 65.9 & 69.2 & 48.9 & 54.9 & 56.0 \\
\hline Chlorite & 0.6 & 1.4 & 1.0 & 1.1 & 1.4 & 1.3 \\
\hline Kaolinite & 0.1 & 2.0 & 0.7 & 1.1 & 0.3 & 5.7 \\
\hline Sum clay minerals & 29.6 & 69.3 & 70.9 & 51.1 & 56.6 & 63.0 \\
\hline \multicolumn{7}{|l|}{ Non-clay silicates } \\
\hline Quartz & 54.6 & 23.9 & 23.5 & 38.8 & 36.5 & 31.0 \\
\hline Plagioclase & 5.1 & 3.7 & 2.7 & 4.4 & 3.9 & 2.0 \\
\hline Alkalifeldspar & 4.3 & 1.8 & 0.5 & 0.7 & 0.4 & 2.2 \\
\hline Opal & 4.1 & & & 1.5 & 0.4 & \\
\hline Clinoptilolite/heulandite & 1.3 & & & & & \\
\hline \multicolumn{7}{|l|}{ Carbonates } \\
\hline Calcite & 0.3 & & 0.9 & 1.7 & & \\
\hline Magnesite & & & & & 0.4 & \\
\hline Ankerite $(0.2 \mathrm{Fe})$ & & & 0.7 & 0.5 & 0.6 & \\
\hline Ankerite (0.54Fe) & & & & 0.3 & 0.3 & \\
\hline \multicolumn{7}{|l|}{ 0xides } \\
\hline Rutile & 0.3 & 0.4 & 0.4 & 0.4 & 0.4 & 0.5 \\
\hline Anatase & 0.2 & 0.4 & & 0.2 & 0.3 & 0.3 \\
\hline \multicolumn{7}{|l|}{ Sulphides } \\
\hline Pyrite & 0.3 & 0.5 & 0.5 & 0.5 & 0.4 & 1.0 \\
\hline Sum non-clay minerals & 70.5 & 30.7 & 29.2 & 49.0 & 43.6 & 37.0 \\
\hline
\end{tabular}

Bold figures are sums of the entries above.

interest with respect to the migration of radionuclides (Aertsens et al., 2008a-c; 0rtiz et al., 2002). The modelling of material physical properties, such as permeability and diffusivity, as well as single and multi-phase fluid flow or radionuclide transport via diffusion and migration requires these data as input (Blunt et al., 2013; Dvorkin et al., 2011; Hemes et al., 2015).

The main objective of this study was to provide the first direct detailed characterisation (qualitative and quantitative) of the 2D pore space in the Ypresian clays. This paper delivers statistical analyses of the pore-space morphologies, including size, shape and orientation of the pores, down to hundreds of nanometers in pore-size diameter.

In the present study, six samples from the 0N-Kallo-1 drilling (2008) were analysed, with respect to their mineral fabrics and porosity, using a combination of broad-ion-beam (BIB) milling and high resolution scanning electron microscopy (SEM), down to nanometre-scale resolution, within representative samples and areas.

Moreover, a high-pressure Wood's metal injection (WMI) experiment, followed by (cooled BIB)-SEM, was carried out to gain information on the connectivity of the pore space in $2 \mathrm{D}$ images (Klaver et al., 2015a).

Results were evaluated and compared to results of previous BIB-SEM studies on the Boom Clay (Hemes et al., 2013, 2015).

\section{Methods and materials}

\section{Methodology}

Mineralogical analysis. For mineralogical characterisation, full quantitative analyses of bulk mineralogy and $<2 \mu \mathrm{m}$ clay fractions were done using $\sim 20 \mathrm{~g}$ per sample for X-ray diffraction (XRD) analysis ( $Q_{\text {mineral }}$ Analysis and Consulting, 2014; Heverlee, Belgium; Tables 1 and 2). The preparation of specimens for XRD analysis is described below.

Samples were first dried at $60^{\circ} \mathrm{C}$ for at least 24 hours. After drying, the samples were ground in an agate/porcelain mortar and part of the homogenised sample $(\sim 2.7 \mathrm{~g})$ was mixed and milled together with an internal standard (Zincite; Zn0) in ethanol, in a micronising mill. Afterwards, the samples were loaded into a sample holder for $\mathrm{XRD}$, using $\mathrm{CuK}_{\alpha}$ radiation. The quantification of the NCMs was performed using the Rietveld method, whereas the quantification of the clay minerals was performed using the PONCKS method (Scarlett \& Madsen, 2006). During Rietveld refinement, an XRD pattern is calculated based on the structural models of the minerals present. The calculated pattern is then fitted to the measured pattern by refining the structural parameters. Quantitative phase contents can be derived from the so-called scale factors, which are refined 
Table 2. Mineralogical compositions of the $<2 \mu \mathrm{m}$ clay fractions from XRD ( $Q_{\text {mineral }}$ Analysis and Consulting, 2014), calculated using the PONKCS-method. Contributions are given in dry wt\%.

\begin{tabular}{|c|c|c|c|c|c|c|}
\hline$<2 \mu \mathrm{m}$ clay fraction & $\begin{array}{l}\text { 0N-Kallo-1- } \\
008-a 1\end{array}$ & $\begin{array}{l}\text { 0N-Kallo-1- } \\
020-a 1\end{array}$ & $\begin{array}{l}\text { 0N-Kallo-1- } \\
045-\mathrm{a} 1\end{array}$ & $\begin{array}{l}\text { 0N-Kallo-1- } \\
\text { 060-a1 }\end{array}$ & $\begin{array}{l}\text { 0N-Kallo-1- } \\
086-c 1\end{array}$ & $\begin{array}{l}\text { 0N-Kallo-1- } \\
\text { 108-a1 }\end{array}$ \\
\hline Illite & 9.0 & 12.0 & 9.0 & 8.0 & 8.0 & 26.0 \\
\hline Smectite & 62.0 & 69.0 & 62.0 & 66.0 & 66.0 & 32.0 \\
\hline Illite/smecite & 27.0 & 18.0 & 27.0 & 25.0 & 24.0 & 27.0 \\
\hline Kaolinite & 0.8 & 0.7 & 0.8 & 0.5 & 0.5 & 14.0 \\
\hline Chlorite & 0.8 & 0.9 & 0.8 & 1.2 & 1.2 & 1.5 \\
\hline
\end{tabular}

during the procedure (Table 1). In a second analysis, the fraction $<2 \mu \mathrm{m}$, enriched in clay minerals, was separated from each of the samples, starting with a modified Jackson treatment (Jackson, 1985), in order to liberate the clay particles. Successively, carbonates, organic matter and Fe oxides/hydroxides were removed from the samples. Afterwards, the fraction $<2 \mu \mathrm{m}$ was separated by centrifugation and the interlayer cations of the separated clay minerals were exchanged to their Ca form. Oriented clay specimens were prepared from the clayenriched $<2 \mu \mathrm{m}$ fractions and measured by XRD in an air-dry, ethylene glycol solvated state.

The obtained diffraction patterns were modeled with the Newmod 2-software (Reynolds \& Reynolds, 2012; Table 2).

Sample drying, water content porosimetry and BIB cross-sectioning. To minimise the development of desiccation cracks during highvacuum BIB milling and SEM imaging, cubic centimetre samples from wet preserved cores (originally of $\sim 20 \mathrm{~cm}$ length and 10 $\mathrm{cm}$ diameter) were slowly dried prior to the analyses. Samples were cut along their bedding using a razorblade. Sub-samples, suitable for BIB milling, had dimensions of $\sim 1 \times 0.5 \times 0.4 \mathrm{~cm}$. Drying was performed at room temperature, in closed containers, over a period of 75-178 days at controlled relative humidity, using different saturated salt solutions (Winston \& Donald, 1960). Five different salt solutions were prepared, ranging from $85 \%$ (potassium chloride, $\mathrm{KCl}$ ), $76-75.5 \%$ (sodium chloride, $\mathrm{NaCl}), 70-71 \%$ (1:1 mixture of $\mathrm{NaCl}$ and $\mathrm{KCl}), 55-53 \%$ (magnesium nitrate hexahydrate, $\left.\mathrm{Mg}\left(\mathrm{NO}_{3}\right)_{2} \cdot 6 \mathrm{H}_{2} \mathrm{O}\right)$ to $33-32.5 \%$ (magnesium chloride hexahydrate, $\mathrm{MgCl}_{2} \cdot 6 \mathrm{H}_{2} 0$ ).

To calculate water content porosities from weight losses, an average grain density of the Ypresian clays of $2.699 \mathrm{~g} / \mathrm{cm}^{3}$ (Van Marcke et al., 2005) and a pore-water density of 1.012 $\mathrm{g} / \mathrm{cm}^{3}$, from pore-water compositions measured at 0N-Kallo-1 (S. Brassinnes, ONDRAF/NIRAS, personal communication, 2014) were used. The resulting water content porosities were $41 \%$, $41 \%, 43 \%, 39 \%, 35 \%$ and $31 \%$, respectively, for the samples $8 a$, 20a, 45a, 60a, 86c and 108a, analysed.

After drying, samples were pre-polished using carbide grinding papers of grit sizes P500-2400 (IS0/FEPA Grit), followed by BIB milling, using a JeoL SM90001 at $6 \mathrm{kV}$ for 8 hours, with the BIB cross-section oriented perpendicular to the bedding. BIB milling removes about $100 \mu \mathrm{m}$ of damaged material and produces smooth, damage-free surfaces, suitable for highresolution SEM image analysis.

Microstructural imaging using SEM (SE2, BSE, EDX). BIB-polished samples were analysed using a Zeiss SUPRA55 scanning electron microscope, equipped with a back-scattered electron (BSE) detector for qualitative mineralogical analysis and a SE2 detector for the analysis of the sample surface topography (mostly the porosity) at high resolution. Energy dispersive XRD (EDX; 0xford Instruments, SDD $\mathrm{X}_{\max } 150$ ) was available for semi-quantitative analysis of the composition.

For qualitative mineralogical, microstructural and pore-space analyses, low-resolution (5000-6000x magnification) BSE and SE2 images were used, allowing for the identification of different mineral phases (BSE images) and characteristic pore-space morphologies (SE2 images; Figs 2-7). For quantitative porosity analysis, SE2-image mosaics, taken at high SEM magnifications $(15,000-30,000 x)$, were used. Image analysis was carried out on areas where macroscopic desiccation cracks were lacking. At the microscopic scale, if desiccation cracks were identified they were manually deleted from the segmentation data and excluded from further statistical analyses. For more details about the method we refer to Hemes et al. (2013).

Porosity evaluation (segmentation and analysis). In SE2 images taken at high magnifications $(15,000-30,000 x)$, pores are segmented semi-automatically, using a combination of thresholding and sobel-edge detection algorithms in Matlab (The MathWorks ${ }^{\circledR}$; after Houben et al., 2013, 2014a; Klaver et al., 2012; Hemes et al., 2013), followed by manual cleaning. The automatic porosity segmentation procedure recognises $\sim 90 \%$ of the resolved pores correctly. Many larger pores contain segmentation artifacts and underestimate the boundary areas of the pores; these data are manually edited in ArcGIS (ESRI Inc., 2011). Prior to further statistical analysis, pores below the practical pore-detection resolution (PPR), as well as drying artifacts, are removed from the data. The PPR defines the minimum amount of pixels per pore that is necessary to confidently recognise the pore. In the present study, the PPR was 
determined as 15 pixels per pore, resulting in pore areas of $1441 \mathrm{~nm}^{2}$ at 30,000x (sample 108a) magnification, $3241 \mathrm{~nm}^{2}$ at 20,000x (samples 20a, 45a and 86c), $5704 \mathrm{~nm}^{2}$ at 15,000x (sample 8a) and 51,509 $\mathrm{nm}^{2}$ at 5000x (sample 60a; Hemes et al., 2013; Klaver et al., 2012).

Pore morphologies are quantified using the Matlab toolbox PolyLX (Lexa, 2010). The most relevant output parameters are the axial ratio $(A R)$, the elongation $(E)$, the roundness $(R)$, the circularity $(C)$, the compactness $(C p)$, the grain-shape factor (GSF) and the orientation angle of the longest pore axis. For pore-morphological analysis we discriminated between intraclay matrix porosity and inter-aggregate pores.

For the analysis of pore-area size distributions, a non-linear binning, as described by Hemes et al. (2013, 2015), Houben et al. (2013, 2014a) and Klaver et al. (2012), of always doubling the subsequent bin size and starting with a bin size of 1 $\mathrm{nm}^{2}$, was used. The resulting pore-area size distributions and contributions of pore-area sizes to total segmented porosities were plotted against the bin centres $\left(b_{i}\right)$. Following the findings of Houben et al. (2013), Klaver et al. (2012) and Hemes et al. $(2013,2015)$, pore-area size distributions in clayey materials can be described by a power law, therefore the frequencies of the pore areas $\left(N_{i}\right)$, that is, the number of pores falling within each bin, were normalised by the respective bin size $\left(S_{i}\right)$ and, for the comparison of pore-area size distributions measured in different samples, the size of the total mosaic area analysed $\left(S_{\text {mosaic }}\right)$. The resulting normalised numbers of pores per bin $\left(N_{i}\right.$ $\left./ S_{i} S_{\text {mosaic }}\right)$ were plotted against the bin centers $\left(b_{i}\right)$ on a double logarithmic scale (Equations 1 and 2).

$$
\begin{aligned}
{\left[N_{i} /\left(S_{i} S_{\text {mosaic }}\right)\right] } & =C\left(b_{i}^{-D}\right) \\
\log \left[N_{i} /\left(S_{i} S_{\text {mosaic }}\right)\right] & =-D \log b_{i}+\log C
\end{aligned}
$$

where $C$ is a constant of proportionality.

To calculate the power-law exponents $(D)$ and $\log (C)$ of the distributions, least-square linear regression analyses (including 95\% confidence bounds) were applied to the linear parts of the pore-area size distributions on a double logarithmic scale and above the PPRs.

Evaluation of the investigated areas' representativeness. Relative errors - with respect to an infinite volume (= $100 \%$ mathematically representative) - of 2D apparent porosities were calculated after Hemes et al. (2015), Keller (2015), Keller et al. (2013) and Kanit et al. (2003) based on the size of the analysed sample areas and the number of realisations $(N)$ of those area elements (see the references above for details). By increasing the number of realisations $(N)$, the area of investigation is virtually increased, thereby decreasing the relative error.

Wood's metal injection experiment. To analyse and directly visualise the connectivity of the pore space, Wood's metal (WM) injection, as an alternative to mercury intrusion porosimetry
(MIP), was used. The advantage of WM over mercury is that it is solid at ambient conditions, but melts above $\sim 70^{\circ} \mathrm{C}$, therefore by heating the whole injection set-up, including the samples, the metal can be injected into the sample's pore space in its liquid state. By cooling down the whole set-up to room temperature afterwards, the injected metal solidifies within the pore space and can be visualised using (cooled BIB)-SEM. The chemical composition of the WM alloy is $\sim 50 \% \mathrm{Bi}, 25 \% \mathrm{~Pb}, 12.5 \% \mathrm{Sn}$ and $12.5 \% \mathrm{Cd}$.

The WMI apparatus used in the present study (after Klaver et al., 2015a) was developed in-house at RWTH Aachen University (Hildenbrand, 2003; Hildebrand \& Urai, 2003). It consists of a pressure cell and two pistons, with external heating and a thermocouple for temperature control during the experiment. A nut and the lower steel piston, with a thread, are used to release the WM cylinder with the injected samples after cooling at the end of the experiment. For WMI, a solid WM piece is inserted into the pressure cell with the lower piston in place. To melt the WM, the cell is heated to $\sim 75^{\circ} \mathrm{C}$, which is checked using a thermocouple and by visual inspection. Afterwards, the oven-dried samples, with dimensions of $\sim 0.5 \times 0.5 \times 0.5 \mathrm{~cm}$, are inserted into the cylinder and immersed into the molten alloy. The upper piston is put in place and the pressure cell is loaded using a manually-controlled hydraulic press equipped with a pressure gauge. The pressure in the molten WM is increased to a maximum of $\sim 156 \mathrm{MPa}$, so the smallest accessed pore throats should be about $\sim 10 \mathrm{~nm}$ in diameter. This is calculated using Laplace's equation (Washburn, 1921; Equation 3). After the maximum pressure has been reached, the heating is turned off and the system is cooled down to room temperature overnight and at high pressure. The solidified WM cylinder containing the samples is then gently pushed out of the stainless steel cylinder (Klaver et al., 2015a).

$$
P=-4 \gamma \cos \theta / d
$$

For the pore-throat diameter calculation, an interfacial tension $(\gamma)$ of WM of $0.420 \mathrm{~N} / \mathrm{m}$ and a wetting angle $(\theta)$ of $140^{\circ}$ (after Abell et al., 1999; Darot \& Reuschlé, 1999; Hildebrand \& Urai, 2003; Klaver et al., 2015a) were used.

Samples are cut from the WM cylinder at room temperature, followed by pre-polishing, using silicon carbide papers down to grit-size P2400 (IS0/FEPA Grit), to optimise the subsequent BIB-polishing.

To avoid re-melting the WM inside the samples, a Technoorg Linda Co. Ltd. SC-1000 argon-ion beam polisher, equipped with a Peltier module - to keep the temperature below the melting point of WM during the ion-beam milling, that is, the sample stage was maintained at $\sim 40^{\circ} \mathrm{C}$ during the whole experiment was used to produce large, planar cross-sections with low surface roughness. The samples were polished in two subsequent steps and rotated during the ion-milling, as described in Klaver et al. (2015a). 


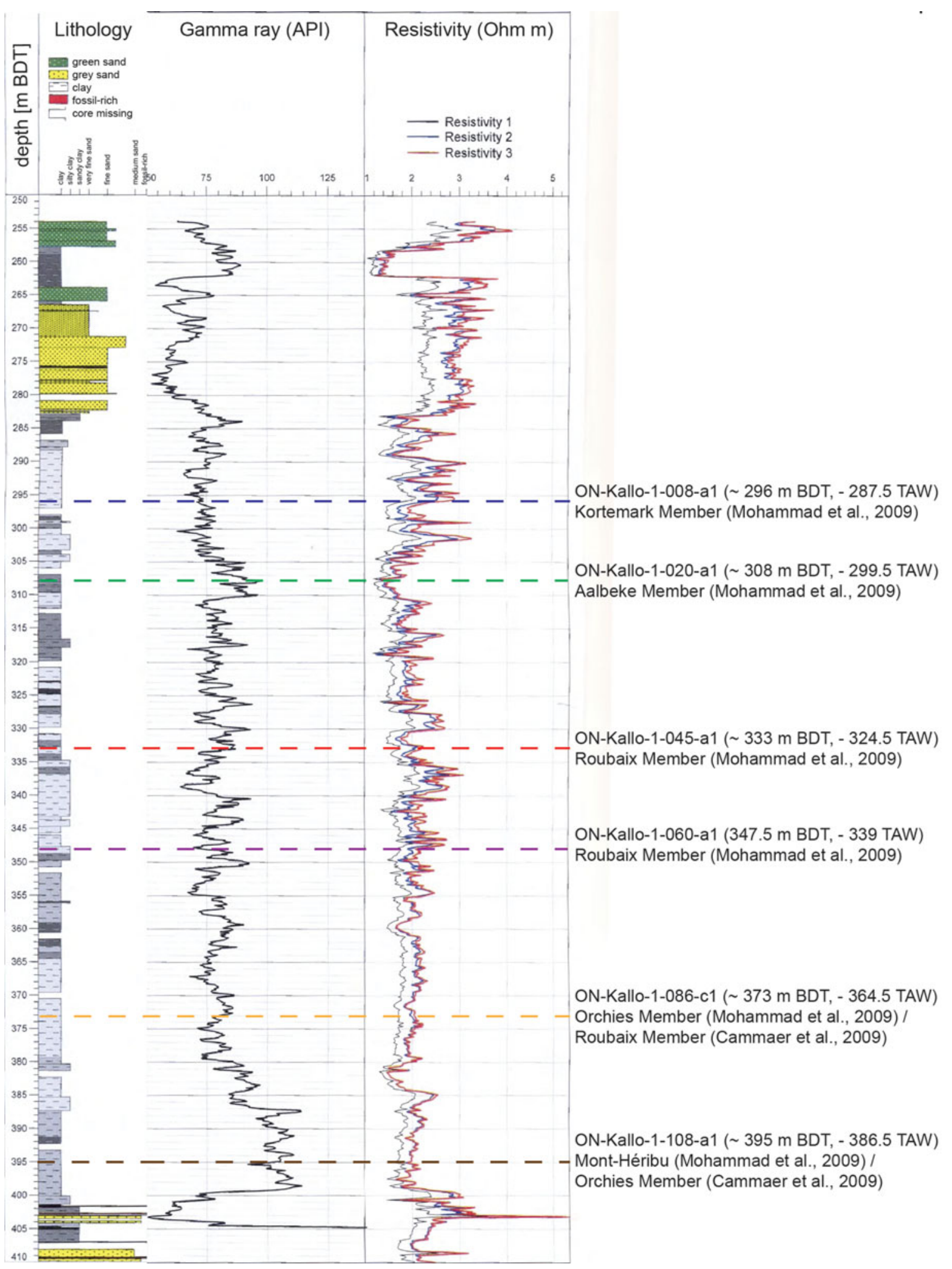

Fig. 1. Stratigraphy, lithology and depths of origin (m BDT) of the Ypresian clay samples investigated in the present study. Figure modified from Mohammad (2009), after Hemes (2015).

\section{Samples}

The Ypresian clays. The Ypresian clays - part of the Eocene Ieper Group - were deposited predominantly in a marine environment during the oldest age of the Eocene (i.e. the Ypresian Age) 255-49 Ma ago (ONDRAF/NIRAS, 2001; Steurbaut, 1998). They comprise the clayey deposits of the Kortrijk Formation and the clay-rich silts of the lower part of the Tielt Formation, referred 


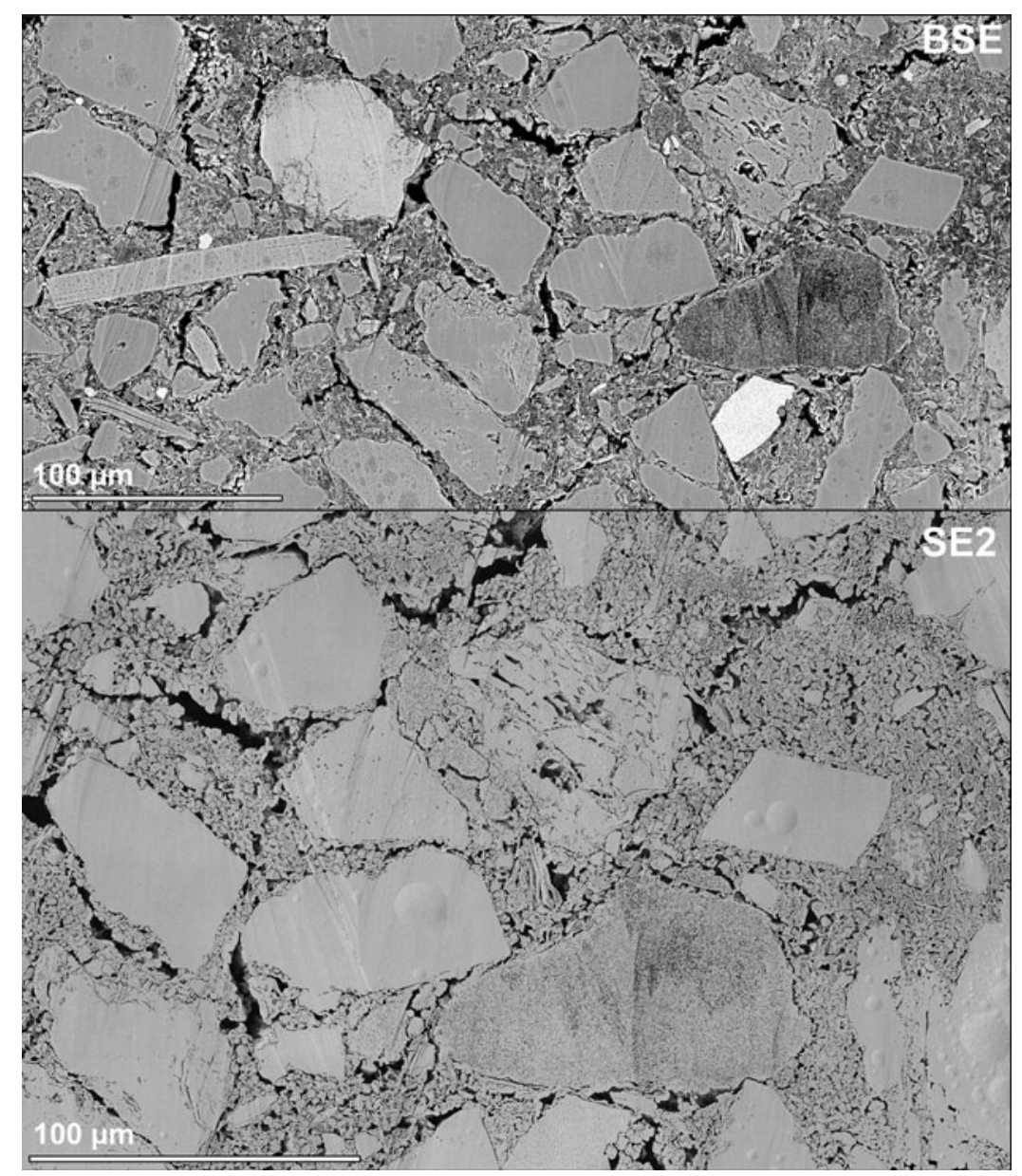

Fig. 2. BSE- and SE2-image overviews of the areas used in the present study for detailed mineralogical and microstructural porosity analyses of the Ypresian clay sample $8 a$.

to as the Kortemark Member, which were both deposited during the early to middle Ypresian (Van Marcke et al., 2005). The deposits are present underneath nearly the whole of Belgium, parts of France and small areas of the Netherlands at depths ranging from the surface to $\sim 650 \mathrm{~m}$ below tweede algemeene waterpassing (TAW), that is, the second general levelling in Belgium (Jones, 1949; Labat, 2011). They dip gently to the north-northeast (Van Marcke et al., 2005). The thickness of the deposits varies between $\sim 50 \mathrm{~m}$ in the south and $\sim 150 \mathrm{~m}$ in the north. Similar to the Boom Clay Formation, the Ypresian clays consist of an alternation of clay- and silt-rich layers, with the corresponding variation in grain size distribution (Van Marcke et al., 2005). First results of quantitative mineralogical analyses on the Ypresian clays, from the Doel-1 well (1998), are summarised in Van Marcke et al. (2005).

Samples analysed in the present study. All samples analysed in the present contribution originate from the 0N-Kallo-1 (2008) well at depths between -288 and $-387 \mathrm{~m}$ TAW, within the Kortemark Member and Kortrijk Formation (Fig. 1). Samples were chosen from the Kortemark Member, Aalbeke Member, Roubaix Member and Orchies/Mont-Héribu Member (Cammaer et al., 2009; Mohammad, 2009; 0NDRAF/NIRAS, 2013b), comprising different mineralogical compositions and grain-size dis- tributions, and being representative of more clay-rich, finegrained vs more NCM and silt-rich, low vs high-porosity material. Six samples were analysed in total. Two samples were very fine grained and show high clay mineral contents (Table 1; samples 0N-Kallo-1-108-a1 and 0N-Kallo-1-045-a1), originating from depths of $\sim 395 \mathrm{mBDT} /-387$ mTAW (sample 108a) and $333 \mathrm{mBDT} /-325 \mathrm{mTAW}$ (sample 45a), respectively. Sample 0N-Kallo-1-020-a1 was of intermediate grain-size and was collected at a depth of $\sim 308 \mathrm{mBDT} /-300$ mTAW. Three samples were more coarse grained (samples 0N-Kallo-1-008-a1, 0NKallo-1-060-a1 and 0N-Kallo-1-086-c1), originating from depths of about $296 \mathrm{mBDT} /-288 \mathrm{mTAW}$ (sample 8a), $348 \mathrm{mBDT} /-340$ mTAW and $\sim 373 \mathrm{mBDT} /-365$ mTAW (sample $86 \mathrm{c}$ ), respectively. Fig. 1 shows the depths of origin of the Ypresian clay samples analysed (in mBDT), together with the lithology of the Ypresian clays at 0N-Kallo-1 (after Mohammad, 2009; Hemes, 2015).

\section{Results}

\section{Full quantitative analysis of the chemical compositions}

Quantitative XRD results indicate comparable overall mineralogical compositions of the samples, but with varying proportions 


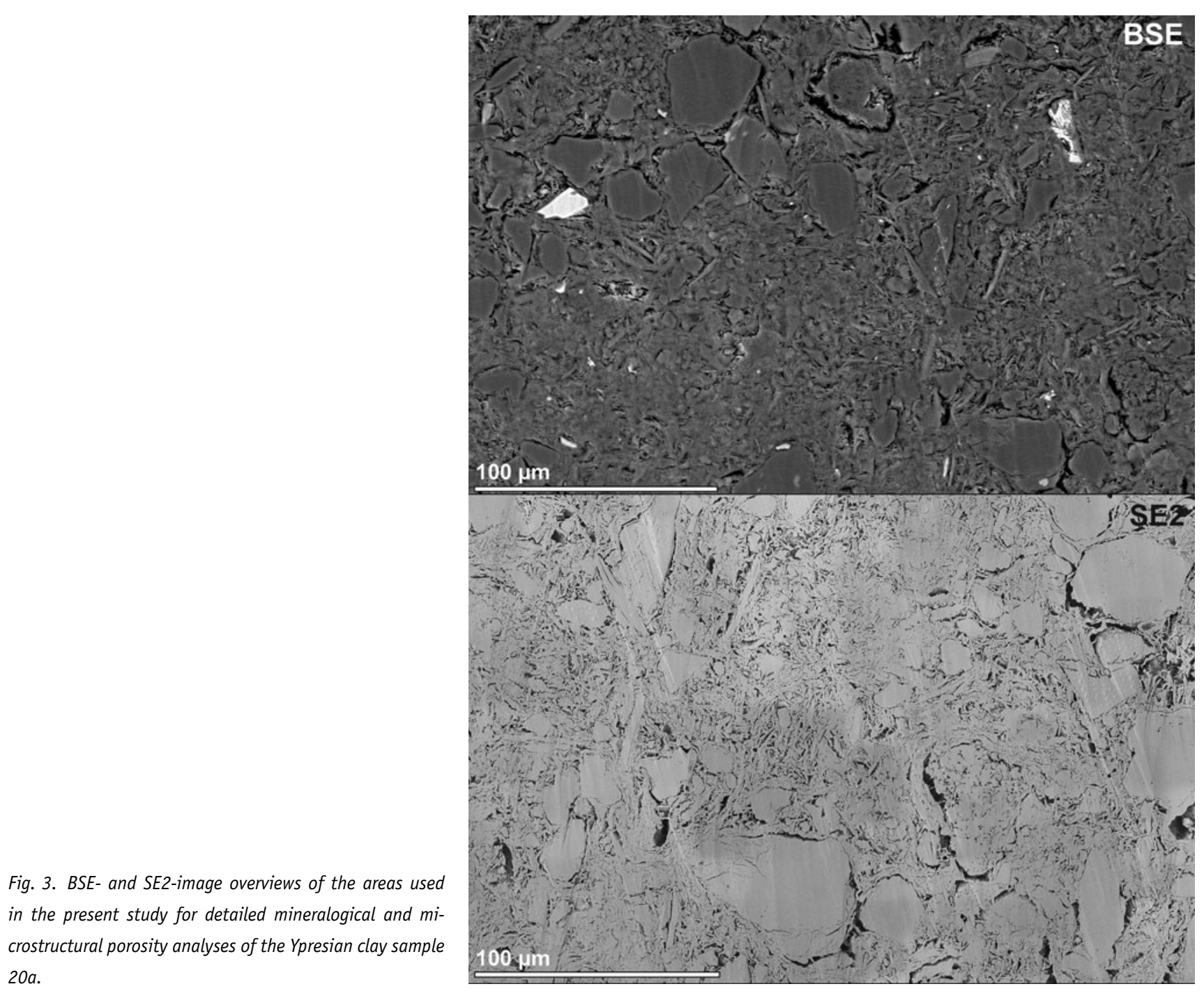

of the different mineral phases (Tables 1 and 2). Clay mineral contents range between 29.6 dry wt\% in sample 8 a (clay-poor) and $\sim 71$ dry wt\% in sample 45 a (most clay-rich). Sample 20a shows a clay mineral content of $\sim 69$ dry wt $\%$ and is therefore also considered to be clay-rich, whereas samples $60 \mathrm{a}, 86 \mathrm{c}$ and 108a show intermediate clay mineral contents between 51 and 63 dry wt\% (Table 1).

Mineralogical analyses using XRD and subsequent quantification of the NCMs by the Rietveld method as well as quantification of the clay minerals by the PONCKS-method result in three different groups of clay minerals, present in significant amounts. These comprise 2:1 clays or TOT phyllosilicates, which are smectite, illite or illite-smectite mixed layer clays. The second group consists of kaolinites, referred to as T0 or 1:1 clays, and the third of chlorites. Kaolinites and chlorites are present in much lower quantities of between 0.1 to 2 dry wt $\%$, compared to the 2:1 clays, accounting for between 28.9 and 69.2 dry wt\% (Tables 1 and 2). Only sample 108a shows a higher kaolinite content of $\sim 5.7$ dry wt\% (bulk sample) and $\sim 14$ dry wt $\%$ in its
$<2 \mu$ m clay fraction, whereas the other samples investigated contain $<1$ dry wt $\%$ kaolinite in their $<2 \mu$ m clay fractions (Tables 1 and 2). Chlorite is limited to the $<2 \mu$ m clay fraction in all samples, with concentrations between 0.8 and 1.5 dry $\mathrm{wt} \%$ (Tables 1 and 2). The 2:1 clays in the $<2 \mu \mathrm{m}$ fractions consist mainly of smectites ( 32-69 dry wt\%) and illite-smectite mixed layer clays (between 18 and 27 dry wt\%). Illite is also present in the $<2 \mu \mathrm{m}$ clay fraction of the samples, but in much lower quantities of between 8 and 12 dry wt\%. Again, sample $108 \mathrm{a}$ is the exception, with a much higher illite content of $\sim 26$ dry wt $\%$ and remarkably less smectite, contributing to only $\sim 32$ dry $w t \%$ of the $<2 \mu$ m clay fraction of the sample (Table 2 ).

Although only the clay minerals were quantified in the oriented clay specimens, reflections of other minerals could also be identified. Among these are zeolites (clinoptilolite or heulandite) in sample $8 \mathrm{a}$, concentrated in its $<2 \mu \mathrm{m}$ clay fraction. 0 pal was identified in the bulk diffraction patterns of the $<2 \mu$ m clay fractions of samples $8 \mathrm{a}, 60 \mathrm{a}$ and $86 \mathrm{c}$, with concentrations inversely correlated to the clay mineral contents. 


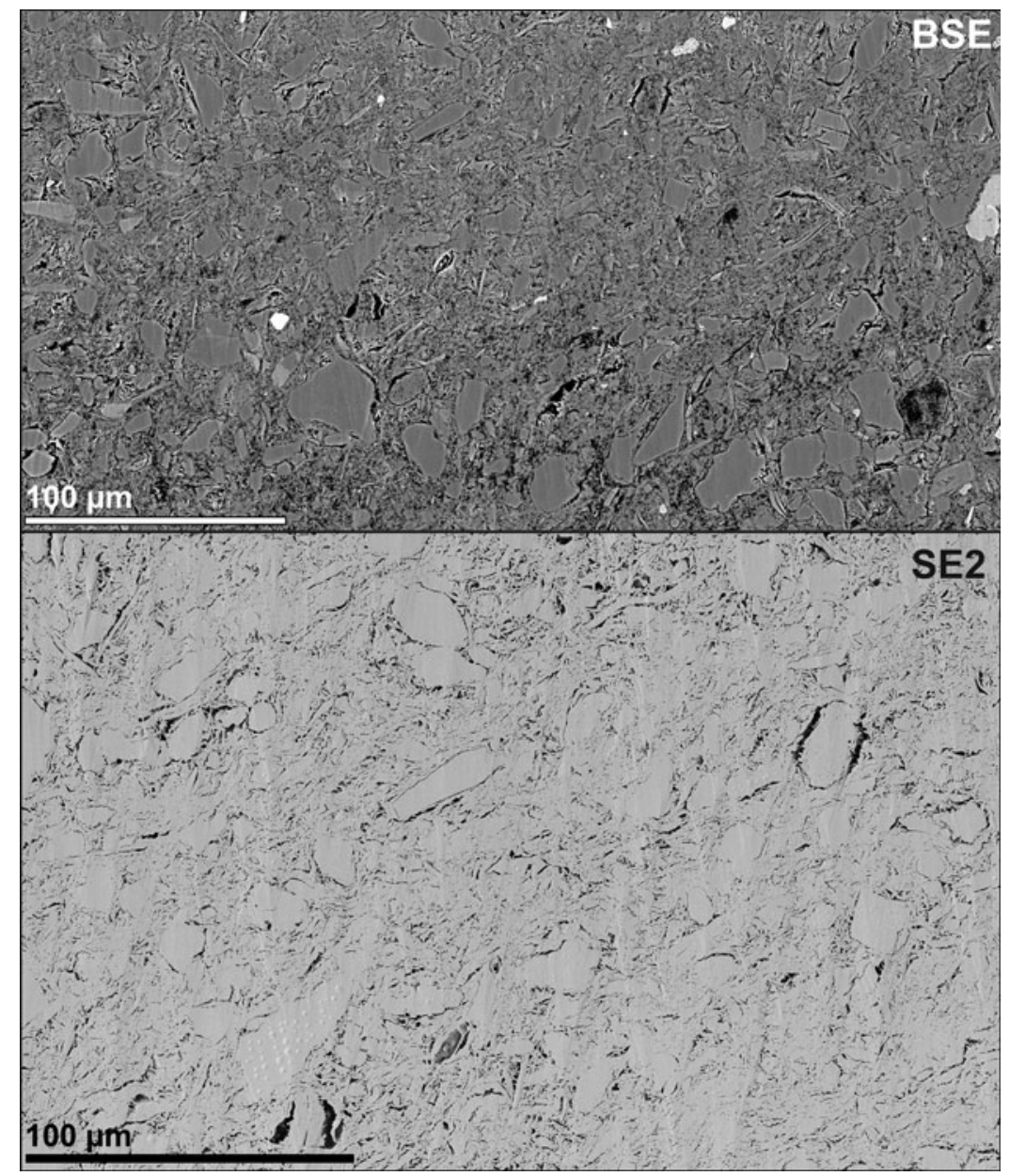

Fig. 4. BSE- and SE2-image overviews of the areas used in the present study for detailed mineralogical and microstructural porosity analyses of the Ypresian clay sample $45 a$.
In the clay-rich samples 20a, 45a and 108a, no opal was found at all. Quartz was detected in all samples analysed, showing concentrations between 23.5 dry $w t \%$ (sample 45a) and 54.6 dry $w t \%$ (sample 8a). An inverse correlation between the amount of plagioclase and the samples' clay mineral contents (Table 1) was observed, showing the highest plagioclase concentrations of 3.9-5.1 dry wt\% in the most clay-poor samples (8a, 60a and 86c). Only sample 108a shows a lower plagioclase content than samples 20a and 45a, although its clay mineral content is lower too. Alkali-feldspars were found in rather high concentrations in samples $8 \mathrm{a}(\sim 4.3 \mathrm{dry} w \mathrm{wt} \%), 108 \mathrm{a}(\sim 2.2 \mathrm{dry} \mathrm{wt} \%)$ and 20a ( 1.8 dry wt\%), but in much lower concentrations of only $\sim 0.4-0.7$ dry wt $\%$ in the remaining samples. The carbonates calcite and ankerite were identified in low concentrations $(<2$ dry wt\%) in samples $8 \mathrm{a}, 45 \mathrm{a}, 60 \mathrm{a}$ and $86 \mathrm{c}$. Magnesite was found in sample $86 c(\sim 0.4$ dry wt\%), only. Rutile, anatase and pyrite were present in concentrations $\leq 1$ dry wt $\%$ in most of the samples analysed (Table 1).

From bulk sample mineralogical compositions and results of XRD analyses of the $<2 \mu \mathrm{m}$ clay fractions, total expanding clay mineral contributions (i.e. smectites + illite-smectite mixed layer clays) were calculated. The expanding clay mineral content of a sample is of importance with respect to the volume change potential of clay minerals during drying/wetting, respectively, and therefore there is the potential for the development of desiccation cracks. Results give bulk expanding clay mineral contents of 26 dry wt $\%$ in sample $8 \mathrm{a}, 60 \mathrm{dry} w \mathrm{w} \%$ in sample 20a, 63 dry wt\% in sample $45 a, 47$ dry wt\% in sample $60 \mathrm{a}, 51 \mathrm{dry}$ wt\% in sample $86 \mathrm{c}$ and $37 \mathrm{dry}$ wt\% in sample 108a. For the calculation, only the contributions of mica from the 2:1 fractions of the bulk were taken into account (but not to the $<2 \mu \mathrm{m}$ clay fractions). Recent analysis of the swelling properties of the Ypresian clays, performed on the same cores, confirms our results based on XRD measurements.

\section{Qualitative description of the morphology of porosity}

Analysis of BSE- and SE2-image mosaics. BSE- and SE2-image mosaics, taken at SEM magnification between 5000 and 30,000x, cover areas between $150 \times 250$ and $200 \times 300 \mu \mathrm{m}^{2}$ (Figs 27). Only the SE2-image area analysed for sample 108a is slightly smaller $\left(\sim 150 \times 200 \mu \mathrm{m}^{2}\right.$; Fig. 7$)$. The images show the characteristic mineral and pore fabrics of the Ypresian clay 


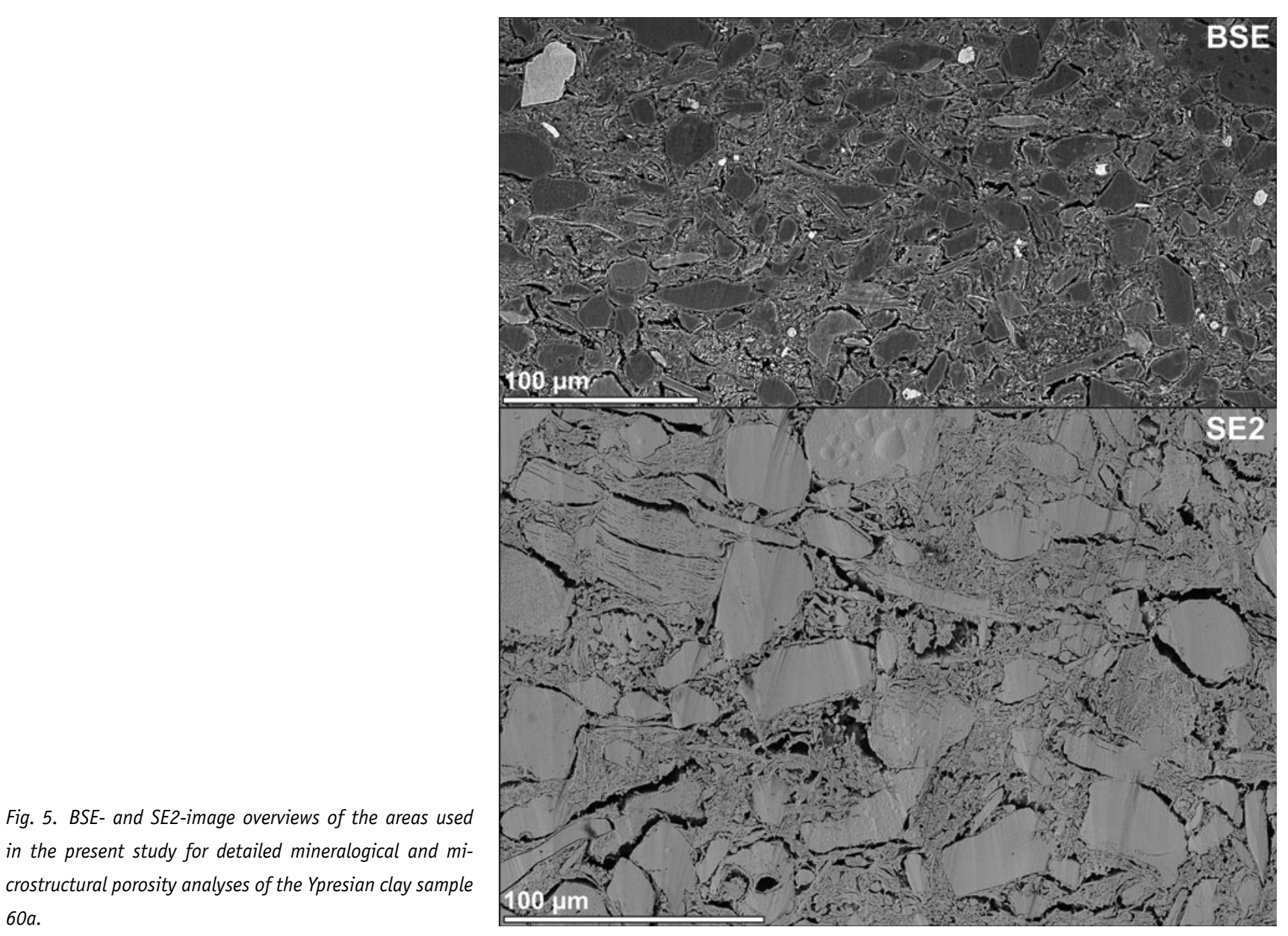

Fig. 5. BSE- and SE2-image overviews of the areas used in the present study for detailed mineralogical and mi$60 a$

samples analysed. The overall microstructures of the samples can be described as consisting of a very fine-grained clay matrix, embedding different relative contributions of larger, siltto sand-sized particles, corresponding to NCM and mostly quartz grains. From the analysis of 2D BIB-SEM cross-sections, sample $8 \mathrm{a}$ displays the most coarse-grained fabric, with apparent grain diameters ranging from clay-sized particles (i.e. $<3.9 \mu \mathrm{m}$ in grain diameter), up to fine sand-sized particles with apparent grain diameters $>63 \mu \mathrm{m}$ (Fig. 2). The remaining coarse-grained samples $60 \mathrm{a}$ and $86 \mathrm{c}$ show very similar apparent grain-size distributions, with a large amount of silt-sized particles (between 3.9 and $63 \mu \mathrm{m}$ ), but also significant contributions of fine-grained, clayey material ( $<3.9 \mu \mathrm{m}$ grain diameter), filling the space in between the larger, NCM grains (Figs 5 and 6). Moreover, the coarse-grained Ypresian clay samples (8a, 60a and $86 \mathrm{c}$ ) show a very loose packing of the material, which is contra-intuitive to the rather high depths of origin of the samples (Figs 1, 2, 5 and 6). The microstructures of the two most fine-grained Ypresian clay samples (45a and 108a), but in particular of sample 108a, are much more compacted. Sample 108a, moreover, shows a lower total BIB-SEM visible porosity than all other samples investigated (Fig. 7). The microstructures of the more fine-grained Ypresian clay samples (20a, 45a and 108a) show characteristic features similar to the typical microstructures and pore morphologies described for fine-grained, clay-rich Boom Clay by Hemes et al. (2013). These samples' microstructures are dominated by a very fine-grained clay matrix (<3.9 $\mu \mathrm{m}$ grain diameters), embedding only a few larger, silt-sized particles, whereas the microstructures of the coarsegrained Ypresian clay samples 8a, 60a and 86c are dominated by larger, silt- to sand-sized particles, with a fine-grained clay matrix filling the space in between (Figs 2-7). Two main classes of porosity were identified:

(1) Pores within the clay matrix, with typical diameters smaller than $1 \mu \mathrm{m}$, showing elongated pore morphologies and high aspect ratios as well as large elongation factors in the finegrained samples 20a, 45a and 108a (Figs 3, 4, 7 and 8A,B), in contrast to much more circular, roundish pores, with low aspect ratios, higher circularities and higher roundness values, recognised in the clay matrix of the more coarsegrained samples analysed (8a,60a and 86c; Figs 2, 5, 6 and $8 C)$. All samples display poor preferential orientations of the clay aggregates and therefore also the pores' longest axes within the clay matrix show no preferred orientation. 


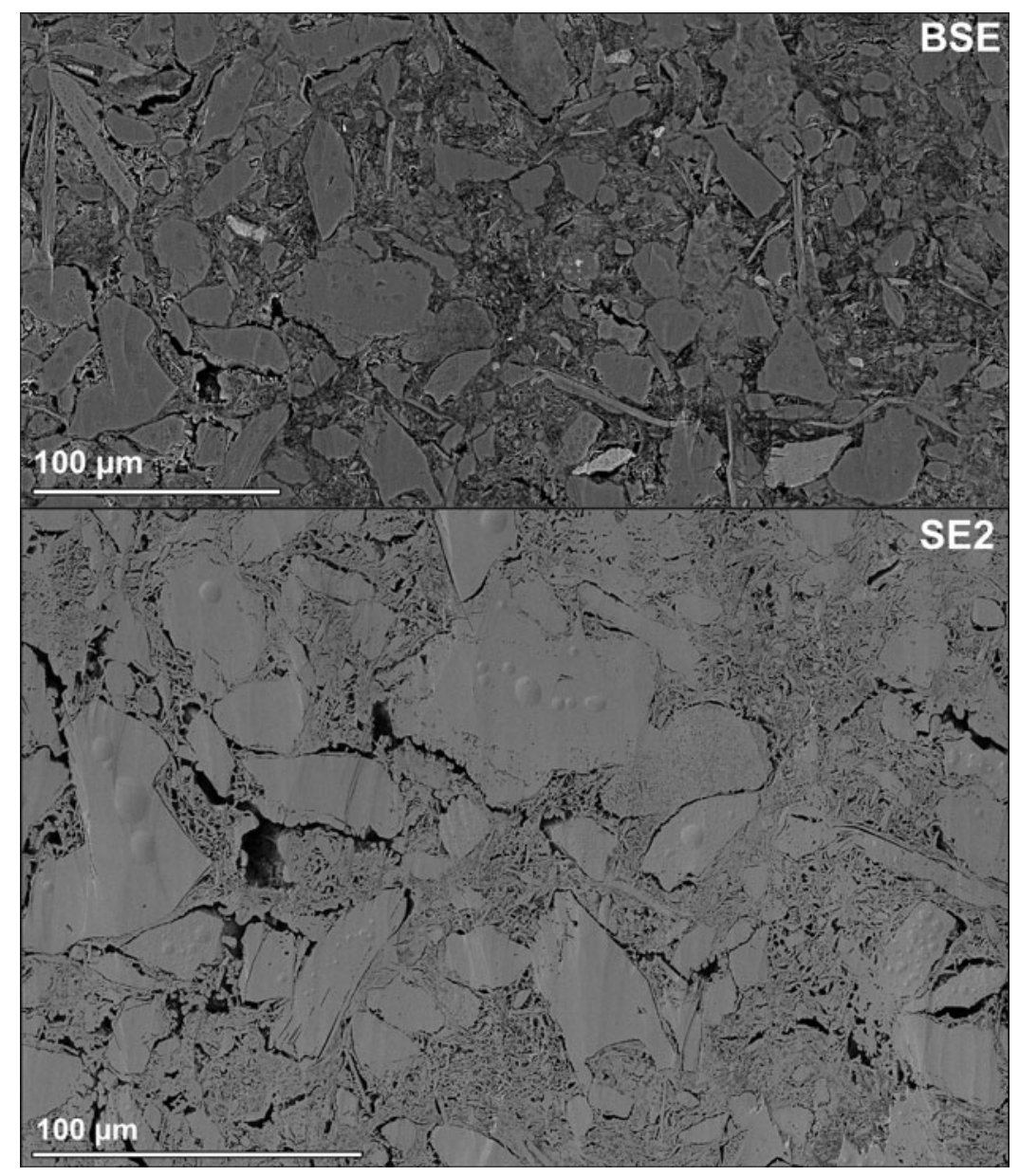

Fig. 6. BSE- and SE2-image overviews of the areas used in the present study for detailed mineralogical and microstructural porosity analyses of the Ypresian clay sample $86 c$.

(2) Larger inter-aggregate pores are found at the interfaces between clay matrix and NCM grains, with typical diameters above 1 up to $10 \mu \mathrm{m}$ (Figs 2-7 and 9).

A more detailed inspection of these inter-aggregate pores shows that they can be further sub-divided into two classes:

(i) Symmetric pores, showing rather high aspect ratios and serrated pore boundaries and resembling desiccation cracks, as described by Renard (2012), Houben et al. (2014b) and Desbois et al. (2014).

(ii) Pores with smooth, rounded pore boundaries, coated by a very low porous, thin $(\sim 1-3 \mu \mathrm{m})$ clay layer (Fig. 9). Compared to the clay matrix, EDX analysis indicates enrichment in titanium (Ti) and sodium (Na) in these coatings, but a slight depletion in aluminum $(\mathrm{Al})$, potassium $(\mathrm{K})$ and iron (Fe) (Fig. 9).

The loose packing of the coarse-grained samples (8a, 60a and $86 \mathrm{c})$, their high clay matrix internal porosities, together with the smooth, rounded pore morphologies were described and characterised as a 'flower like microstructure' (Hemes, 2015; Figs 2, 5 and 6).

\section{Wood's metal injection}

WMI was carried out on one Ypresian clay sample (ON-Kallo1-020a). Because of the high density of the WM, it appears bright in BSE images (Fig. 10) and the results show that nearly the entire resolved pore space was filled by the WM alloy, with only a few cracks remaining unfilled (Fig. 10, white arrow). The inset in Fig. 10 shows high-resolution examples of the smallest visible filled pores. WMI reveals that all pores - including pores within the clay matrix as well as inter-aggregates pores - are mutually connected at a maximum WM entry pressure of $156 \mathrm{MPa}$, corresponding to accessible pore-throat diameters of $10 \mathrm{~nm}$.

\section{Quantitative description of porosity}

Visible porosity in BIB-SEM images. Total BIB-SEM observed porosities, resulting from automatic porosity segmentations on SE2-image mosaics at resolutions between $51,509 \mathrm{~nm}^{2}$ at $5000 \mathrm{x}$ magnification and $1441 \mathrm{~nm}^{2}$ at 30,000x magnification, are between $6.3 \%$ of the analysed area for sample $108 \mathrm{a}(30,000 \mathrm{x})$ and $17.8 \%$ for sample $60 \mathrm{a}(20,000 \mathrm{x})$. At $5000 \mathrm{x}$ magnification sample 60 a shows a total porosity of $14.8 \%$ and sample $8 a$ of $13.9 \%$. At $15,000 x$ SEM magnification sample $8 \mathrm{a}$ shows a 
Fig. 7. BSE- and SE2-image overviews of the areas used in the present study for detailed mineralogical and microstructural porosity analyses of the Ypresian clay sample $108 a$.

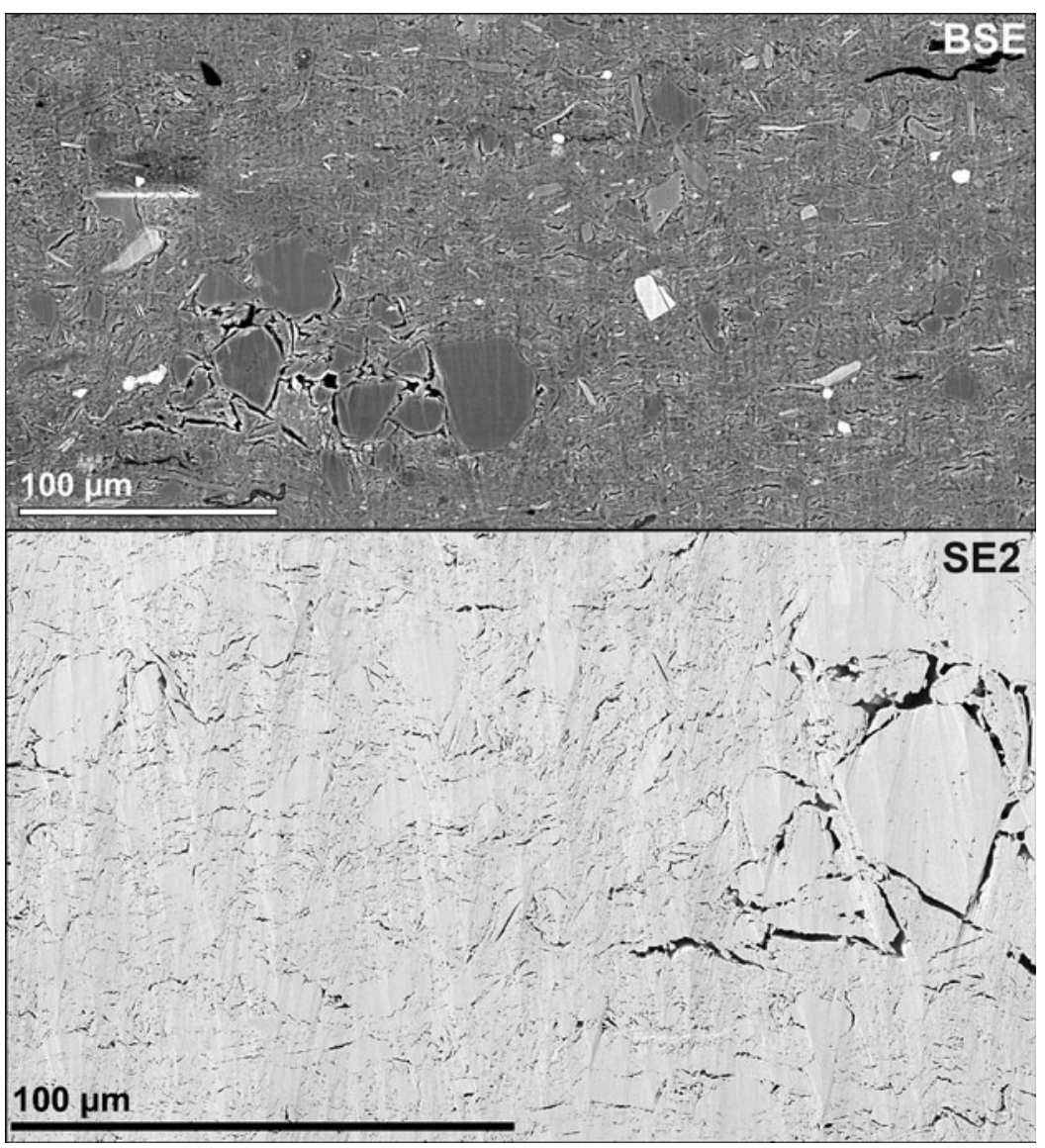

total segmented porosity of $15.2 \%$ and at $20,000 \mathrm{x}$ magnification sample 20a shows a total porosity of $9.9 \%$, sample $45 \mathrm{a}$ of $9.2 \%$ and sample $86 \mathrm{c}$ of $14.5 \%$. Due to timely restrictions, manual cleaning of the segmentation data was only carried out on the high-resolution data of samples $8 \mathrm{a}$ and $86 \mathrm{c}$, and resulted in total BIB-SEM observed porosities of $17.3 \%$ for sample $8 \mathrm{a}(15,000 \mathrm{x}$ magnification) and $16 \%$ for sample $86 \mathrm{c}(20,000 \mathrm{x}$ magnification). Manually cleaned segmentation data are considered to provide a more realistic visible porosity at the scale of observations. On average, the visible porosities, inferred from manually cleaned data, may increase up to $15 \%$ with respect to the non-cleaned data. However, an increase in BIB-SEM visible porosity with the sample grain size and NCM content, can be inferred both, from the manually cleaned as well as from the non-manually cleaned data.

Relative errors of porosity measurements. For areas analysed in the present contribution and one realisation $(N=1)$, calculated relative errors are between 8 and 23\% (Table 3). By increasing the number of realisations to 10 , relative errors would be reduced to between 2.5 and $7.5 \%$, and with a total number of 100 realisations, the relative errors of porosity estimations would be $\leq 2.5 \%$ for all samples analysed (Table 3 ).

Pore-shape analysis. For pore-shape analysis, pores within the clay matrix, which are smaller than $1 \times 10^{7} \mathrm{~nm}^{2}$ pore area, were analysed separately from the larger inter-aggregate pores. The results of the quantitative pore-shape analysis are summarised in the following.

In the most fine-grained, clay-rich samples (20a, 45a and 108a), pores within the clay matrix are elongated, with high aspect ratios between 1.8 and 2.7, whereas in the more coarsegrained, NCM-rich samples (8a,60a and 86c), typical pore morphologies within the clay matrix are roundish, with lower aspect ratios between 1.64 and 1.72. The grain- or pore-shape factor (GSF), which describes the irregularity and complexity of a pore boundary, is significantly higher for the segmented interaggregate pores, with values between 5.74 and 10.71, compared to values of $\sim 3-5$ for pores within the clay matrix.

Pore-size distribution analyses. For all samples analysed, the frequency distributions of pore areas show mono-modal distributions (Figs 11 and 12) in the pore-area size range bound by the PPR and the largest pore detected in the image. However, within the same pore-area size range, the contributions of pore sizes (areas) to the total segmented porosities are either monoor bi-modally distributed. The primary peaks in bi-modal porosity contribution distributions (Cttp), observed for samples 8a, $60 \mathrm{a}, 86 \mathrm{c}$ and $108 \mathrm{a}$, as well as the peaks in mono-modal porosity contribution distributions, observed for samples 20a and $45 \mathrm{a}$, are attributed to pores within the clay matrix of these samples (i.e. $<1 \times 10^{7} \mathrm{~nm}^{2}$ pore area). In more detail, those peaks are located at $\sim 1 \times 10^{6} \mathrm{~nm}^{2}$ pore area in samples $8 \mathrm{a}$, 
Table 3. Summary of results of REA calculations.

Relative errors of porosity estimations (\%)

\begin{tabular}{lllcll} 
Sample ID & Area analysed $\left(\boldsymbol{\mu m}^{2}\right)$ & Magnification & $\boldsymbol{N = 1}(\%)$ & $\boldsymbol{N}=\mathbf{1 0}(\%)$ & $\boldsymbol{N}=\mathbf{1 0 0}(\%)$ \\
\hline ON-Kallo-1-008-a1 & $4.65 \times 10^{5}$ & $5,000 \mathrm{x}$ & 9.5 & 3.0 & 1.0 \\
& $2.23 \times 10^{5}$ & $15,000 \mathrm{x}$ & 17.0 & 5.0 & 2.0 \\
0N-Kallo-1-020-a1 & $2.19 \times 10^{5}$ & $20,000 \mathrm{x}$ & 9.0 & 3.5 & 1.5 \\
0N-Kallo-1-045-a1 & $8.04 \times 10^{4}$ & $20,000 \mathrm{x}$ & 10.0 & $3-3.5$ & 1.5 \\
ON-Kallo-1-060-a1 & $2.92 \times 10^{5}$ & $5,000 \mathrm{x}$ & 17.0 & 5.5 & 2.0 \\
& $1.49 \times 10^{5}$ & $20,000 \mathrm{x}$ & 8.0 & 2.5 & $<1$ \\
0N-Kallo-1-086-c1 & $1.99 \times 10^{5}$ & $5,000 \mathrm{x}$ & 23.0 & 7.5 & 2.5 \\
& $1.14 \times 10^{5}$ & $20,000 \mathrm{x}$ & 12.5 & 4.0 & 1.5 \\
0N-Kallo-1-108-a1 & $2.52 \times 10^{4}$ & $30,000 \mathrm{x}$ & 18.0 & 5.5 & 2.0 \\
\hline
\end{tabular}

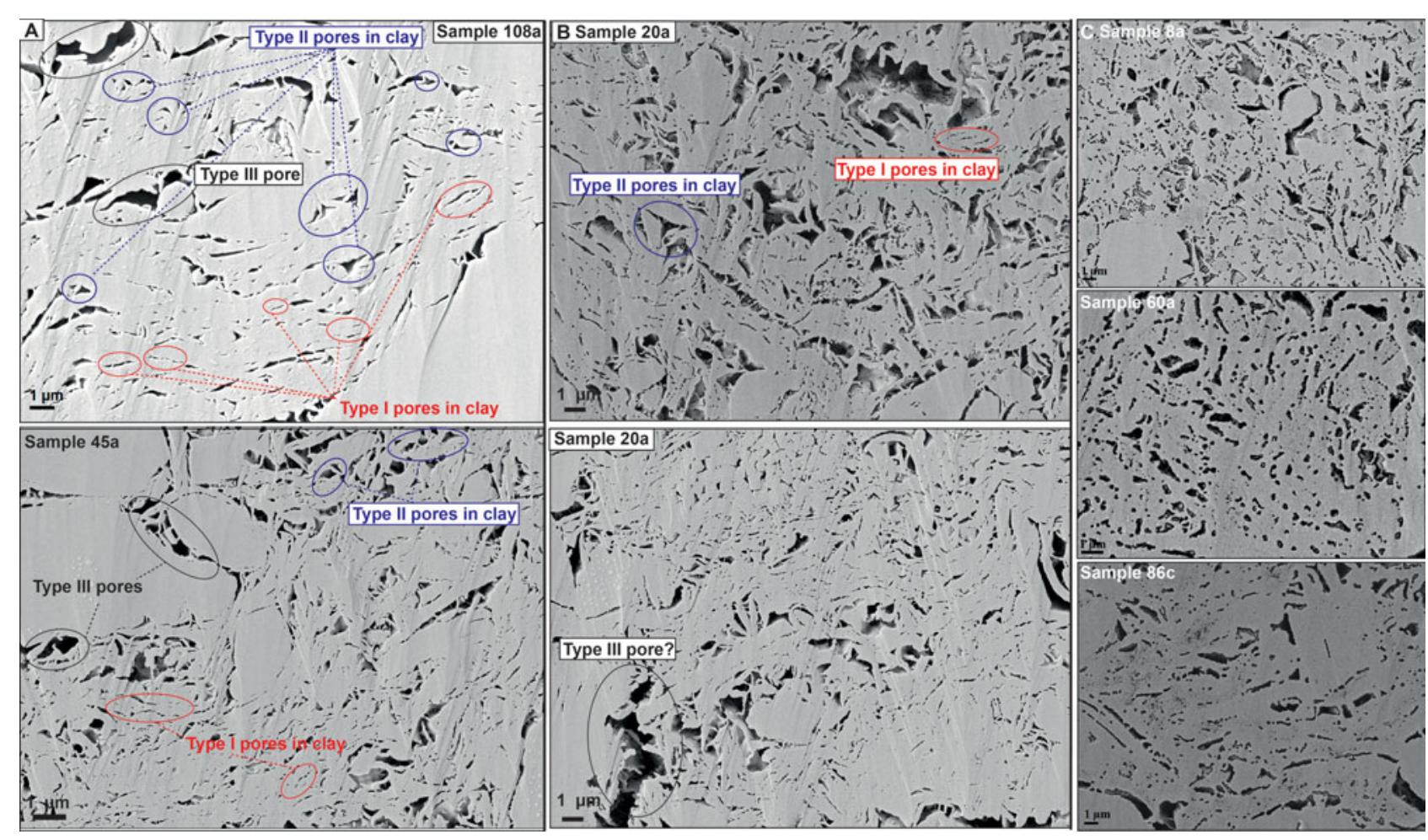

Fig. 8. A. Typical pore morphologies in fine-grained, clay-rich (>60 dry wt\% clay) Ypresian clay samples 108a and 45a, classified according to Desbois et al. (2009) and Hemes et al. (2013) as 'type I-III pores' in clay, which show similar pore morphologies as observed within the clay matrix of the Boom Clay (Hemes et al., 2013); B. Typical pore morphologies within the clay matrix of the Ypresian clay sample 20a, showing less elongated, more roundish pore shapes, but still with similarities to pore morphologies observed within the clay matrix of the Boom Clay. C. Characteristically very small $\left(<3 \times 10^{4} \mathrm{~nm}^{2}\right.$ pore area) circular pores, observed within the clay matrix of the more coarse-grained, NCM-rich (>40 dry wt\% NCM) Ypresian clay samples $8 a, 60 a$ and $86 c$.

20a and $86 \mathrm{c}$ (Figs 11 and 12), $\sim 5 \times 10^{5} \mathrm{~nm}^{2}$ pore area in sample 45a (Fig. 11) and $\sim 2 \times 10^{5} \mathrm{~nm}^{2}$ pore area in sample $108 \mathrm{a}$ (Fig. 12). Sample 60a does not show a clear peak in its porosity contribution distribution, but rather a wide range of pore sizes, contributing significantly to the total segmented porosity (Fig. 12). For samples 8a, 60a and 108a, a secondary peak is displayed in their porosity Cttp, contributing to a significant fraction of the total resolved porosity (Figs 11 and 12). This peak is attributed to larger, inter-aggregate pores, preferentially located at the boundaries between the clay matrix and
NCM grains, and showing characteristic sizes above $1 \times 10^{7} \mathrm{~nm}^{2}$ pore area.

On the right side of Figs 11 and 12, pore-area size distributions, measured within the clay matrix of the samples, are plotted on a double logarithmic scale. Least-square linear regression analysis on the linear parts of these plots (i.e. pores within the clay matrix and above the PPRs of 15 pixels per pore), results in power-law exponents of pore-area size distributions between 1.46 and 1.78 (sample 8a 1.66, sample 20a 1.62, sample 45a 1.63, sample 60a 1.71, sample 86c 1.46, sample 108a 1.78) 

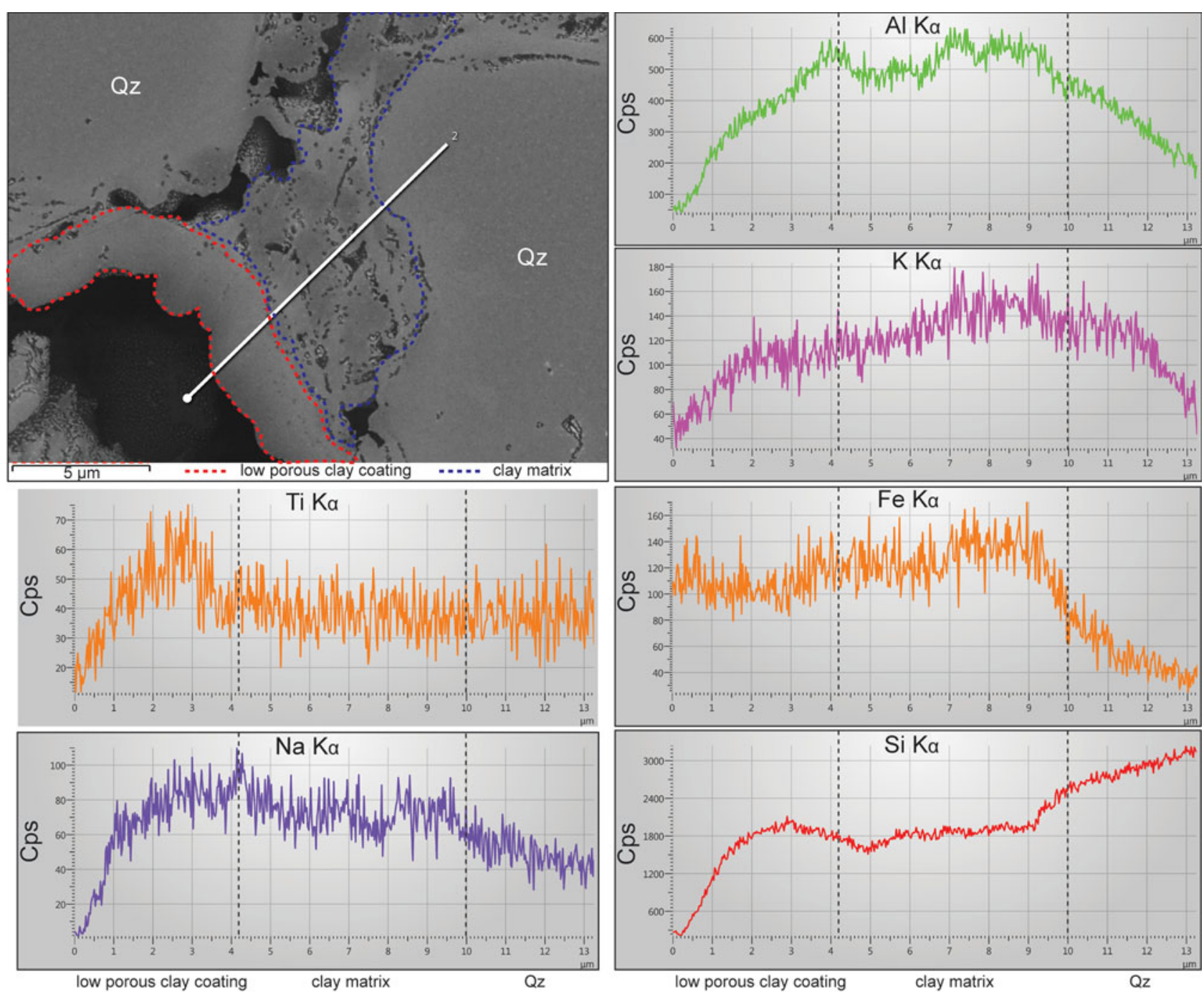

Fig. 9. Results of EDX analyses (line-scan (counts per second)) on thin, low porous clay coatings (dashed red line), observed on large, smooth inter-aggregate pores at the boundaries between the clay matrix (dashed blue line) and NCMs (mostly quartz, Qz) grains, showing a depletion in aluminum (Al), potassium ( $\mathrm{K}$ ) and iron ( $\mathrm{Fe})$, and an enrichment in titanium ( $\mathrm{Ti}$ ) and sodium ( $\mathrm{Na}$ ) compared to the clay matrix.

and $\log C$ values between -4.76 and -3.36 (sample $8 \mathrm{a}-3.70$, sample 20a -3.97, sample 45a-3.88, sample 60a -3.37, sample 86 c -4.76 , sample $108 a-3.36)$. Values of power-law exponents and $\log C$ are all comparable within the $95 \%$ confidence range for all samples analysed (Fig. 13).

\section{Discussion}

\section{Representativeness of the analyses}

Relative errors of porosity estimations are $\sim 10 \%$ for $N=1$ for most of the samples analysed (i.e. sample $8 \mathrm{a}$ at low resolution, 5000x magnification data, and samples 20a, 45a, 60a and 86c at $20,000 \mathrm{x}$ magnification; Table 3). For samples $60 \mathrm{a}$ and $86 \mathrm{c}$ at low magnification $(5000 \mathrm{x})$, sample $8 \mathrm{a}$ at high resolution $(15,000 \mathrm{x}$ magnification) and sample $108 \mathrm{a}(30,000 \mathrm{x}$ magnification), the relative errors of porosity estimations are slightly higher (17$23 \%)$.
For sample 108a, the relative error is higher than for the other fine-grained samples (45a and 20a) due to the area analysed being about an order of magnitude smaller (Fig. 7). A second reason is that the area analysed of sample 108a has a more heterogeneous fabric due to the presence of a cluster of large, silt-sized NCM grains (Fig. 7).

In general, the more coarse-grained samples show higher relative errors of porosity estimations than the fine-grained samples for comparable sizes of analysed areas. This can be explained by the more significant contribution of large, low to non-porous NCM grains to the microstructure of these samples.

We have shown that it is possible to decrease the relative error of porosity estimations by increasing the number of realisations of the analysed area $(N)$ (Table 3 ).

Another aspect to consider when discussing the representativeness of the results is the impact of microscopic drying artifacts (i.e. desiccation cracks) on the porosity estimations from BIB-SEM image analyses (Desbois et al., 2014). However, 


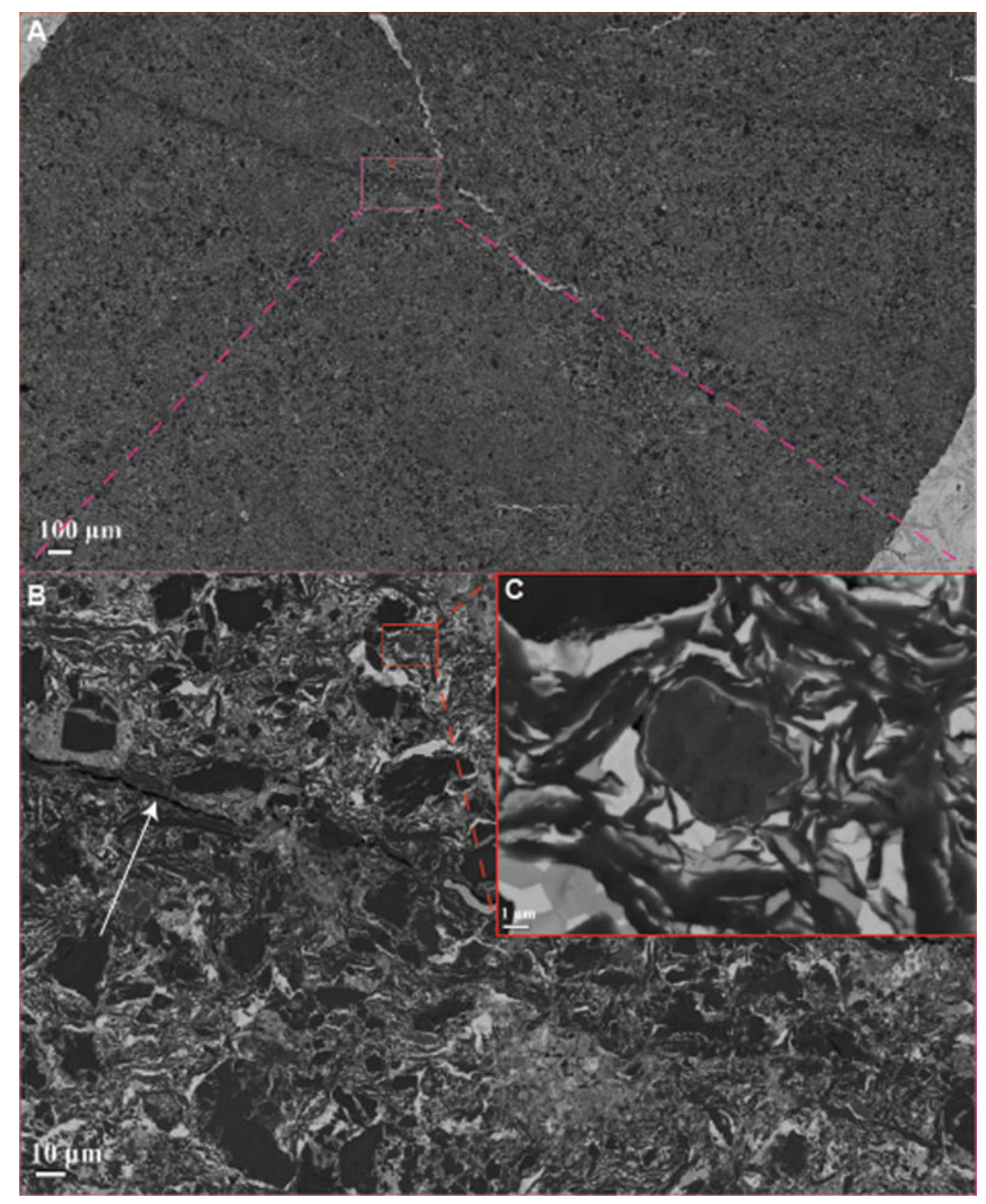

Fig. 10. A. Nearly entirely WM-filled pore space in sample ON-Kallo-1-020a, resolved at BSE-image magnification of $20,000 x ; B$. The white arrow indicates rare cracks, which remained unfilled during the injection procedure and probably developed due to pressure release during unloading of the WM-injected sample (Hemes, 2015); C. Detail of $B$. WM is indicated by the bright phase in the SEM micrograph.
Desbois et al. (2014) have shown that microscopic drying artifacts, which occur at the scale of individual pores, cannot be easily removed from the segmentation data and also do not have a large impact on the overall porosity statistics within the standard deviations.

\section{Pore-size distributions and pore morphologies within the clay matrix of Ypresian clays and comparison to the Boom Clay}

If all pores within the clay matrix of the Ypresian clays, as well as larger inter-aggregate pores, are taken into account, they show similar frequency distributions with small pores dominating the frequency distributions (Figs 11 and 12). On the other hand, large inter-aggregates pores contribute significantly to the porosity volume (Figs 11 and 12). This behavior is comparable to what has been observed for the Boom Clay, analysed by Hemes et al. (2013) (Fig. 14). Fig. 14 resumes the findings by Hemes et al. (2013), re-plotted to be directly comparable to the present study. For all samples analysed (BC and YPRC; Figs 11, 12 and 14), a PPR of 15 pixels and the largest pore-area sizes within the clay matrix of $\sim 1 \times 10^{7} \mathrm{~nm}^{2}$ were considered.
Existing studies on pore-size distributions of the Ypresian clays include SEM-image analyses as well as MIP (Nguyen et al., 2014). They report either mono- or bi-modal pore-size distributions. Mono-modal pore-size frequency distributions show a peak at $\sim 800 \mathrm{~nm}$ pore diameter, corresponding to a minimum equivalent pore area of $\sim 5 \times 10^{5} \mathrm{~nm}^{2}$, within the meso-pore regime. These frequency distributions are characteristic of fabrics dominated by silty grains, referred to as aggregate-type microstructures (Nguyen et al., 2014). Bi-modal pore-size frequency distributions were reported for clay-matrix dominated microstructures, with a first peak occurring at $\sim 60 \mathrm{~nm}$ pore diameter (micro-pore family), corresponding to a minimum equivalent pore area of $\sim 2.8 \times 10^{3} \mathrm{~nm}^{2}$, and a secondary peak observed at $\sim 250 \mathrm{~nm}$ pore diameter (meso-pore family), corresponding to a minimum equivalent pore area of $\sim 1 \times 10^{5} \mathrm{~nm}^{2}$. However, primary peaks in bi-modal porosity distributions, for example as measured by Nguyen et al. (2014), are below the PPRs and therefore not fully accessible in the present study.

Pores within the clay matrix follow power-law pore-area distributions over a range between the PPR and the largest pores observed within the clay matrix $\left(\sim 1 \times 10^{7} \mathrm{~nm}^{2}\right.$ pore area; Figs 11 and 12). This suggests a self-similar behaviour of 


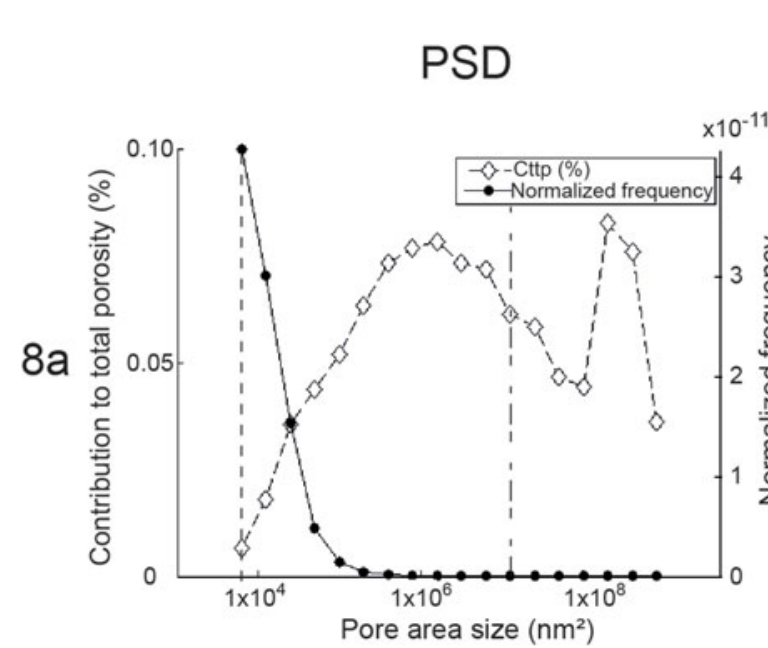

\section{Power-law distribution for pores in clay matrix}
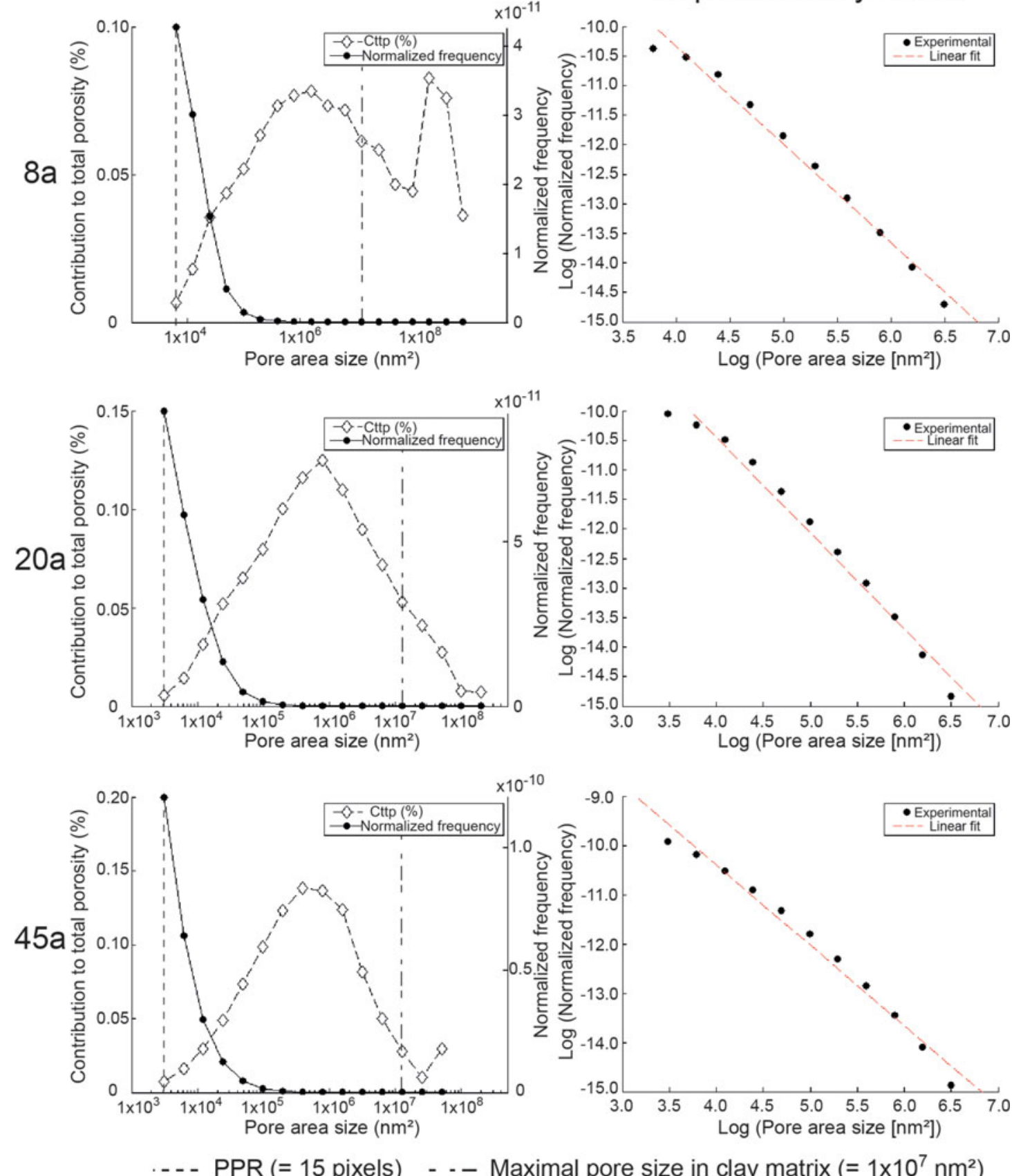

Fig. 11. Pore-area size distribution analyses on the Ypresian clay samples 8a, 20a and 45a. Left: Normalised pore-size frequencies and contributions to total segmented porosities (Cttp (\%)). Right: Power-law distributions of pore-area sizes, within the clay matrix.

porosity within the clay matrix of the Ypresian clays. Powerlaw pore-size distributions and self-similarity of observed microstructures hint towards the possibility of up-scaling of the results to larger scale (micro-) structural features of the Ypresian clays. Power-law distributions of pore-area sizes have also been reported for the Boom Clay (Hemes et al., 2013; Fig. 14) and the Opalinus Clay (Houben et al., 2013, 2014a), as well as for several fine-grained oil and gas shale samples (Klaver et al., 2012, 2015b).
Power-law exponents found for the Boom Clay and Ypresian clays are comparable within the $95 \%$ confidence bounds (Fig. 13), suggesting similar microstructures and physical properties. Morphologically, pore types found within the clay matrix of the Ypresian clays are similar to those found in the Boom Clay, for example by Desbois et al. (2009) and Hemes et al. (2013), where pore types are controlled by the impingement of adjacent clay aggregates: 'elongated "type I pores" are found in between similarly oriented sheets of clay' 


\section{PSD}
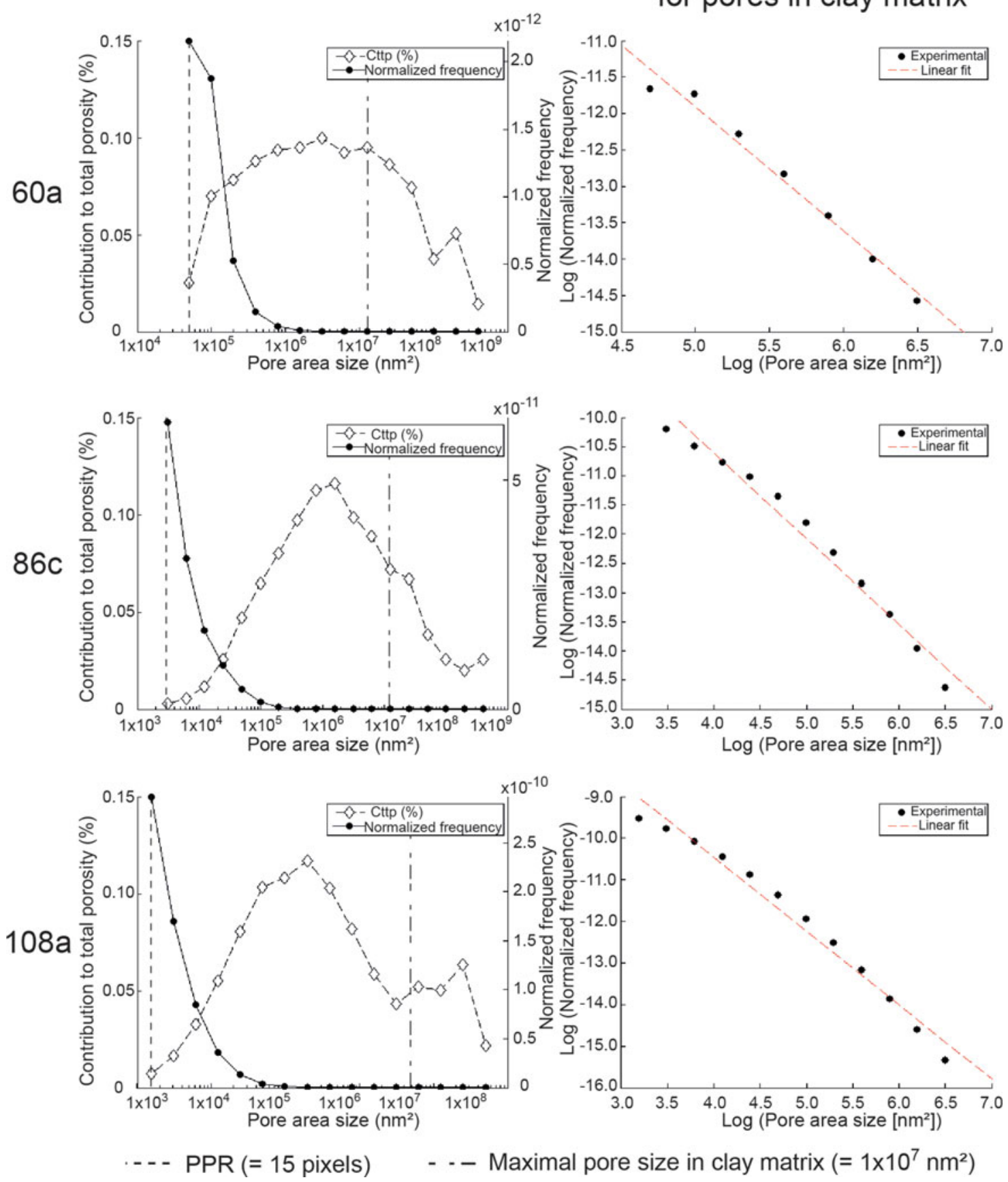

Fig. 12. Pore-area size distribution analyses on the Ypresian clay samples 60a, $86 \mathrm{c}$ and $108 \mathrm{a}$. Left: Normalised pore-size frequencies and contributions to total segmented porosities (Cttp (\%)). Right: Power-law distributions of pore-area sizes, within the clay matrix.

(Desbois et al., 2009) and 'crescent-shaped "type II pores" in saddle-reefs of folded clay sheet' (Desbois et al., 2009). These pores show typical sizes (areas) below $1 \times 10^{6}$ to $1 \times 10^{7} \mathrm{~nm}^{2}$ in the Ypresian clays. Moreover, 'type III pores' in clay, after Desbois et al. (2009) and Hemes et al. (2013), were observed and identified, which can be described as large jagged pores in the strain shadows of clasts' (Desbois et al., 2009), with axial ratios usually $>2$.

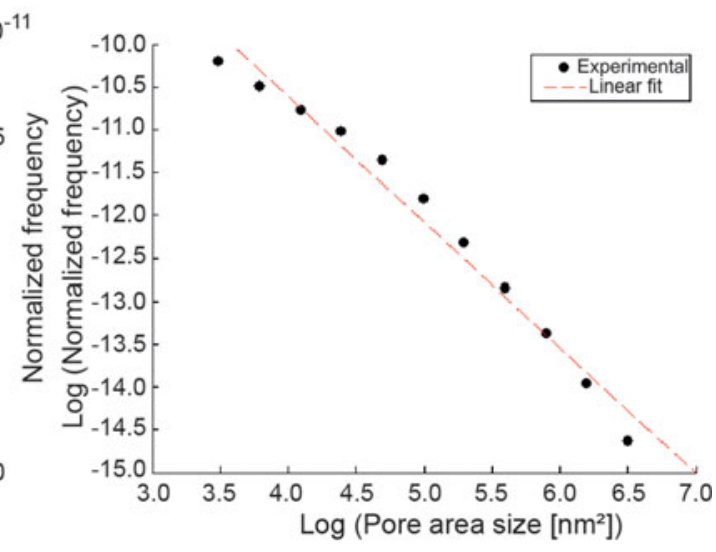

Power-law distribution for pores in clay matrix

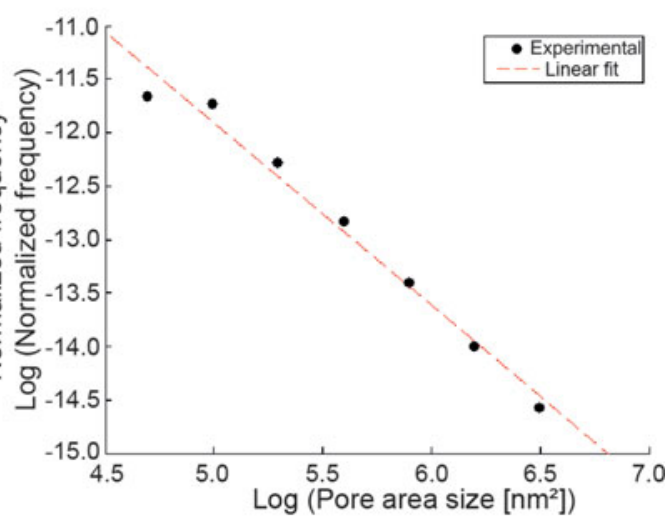

$\left.\mathrm{m}^{2}\right)$ 
Fig. 13. Comparison of power-law scaling parameters (D) from least-square linear regression analysis on pore-area size distributions within the clay matrix, as well as - $\log \mathrm{C}$ values for the Ypresian clays (present study), compared to the Boom Clay (data reworked from Hemes et al., 2013).

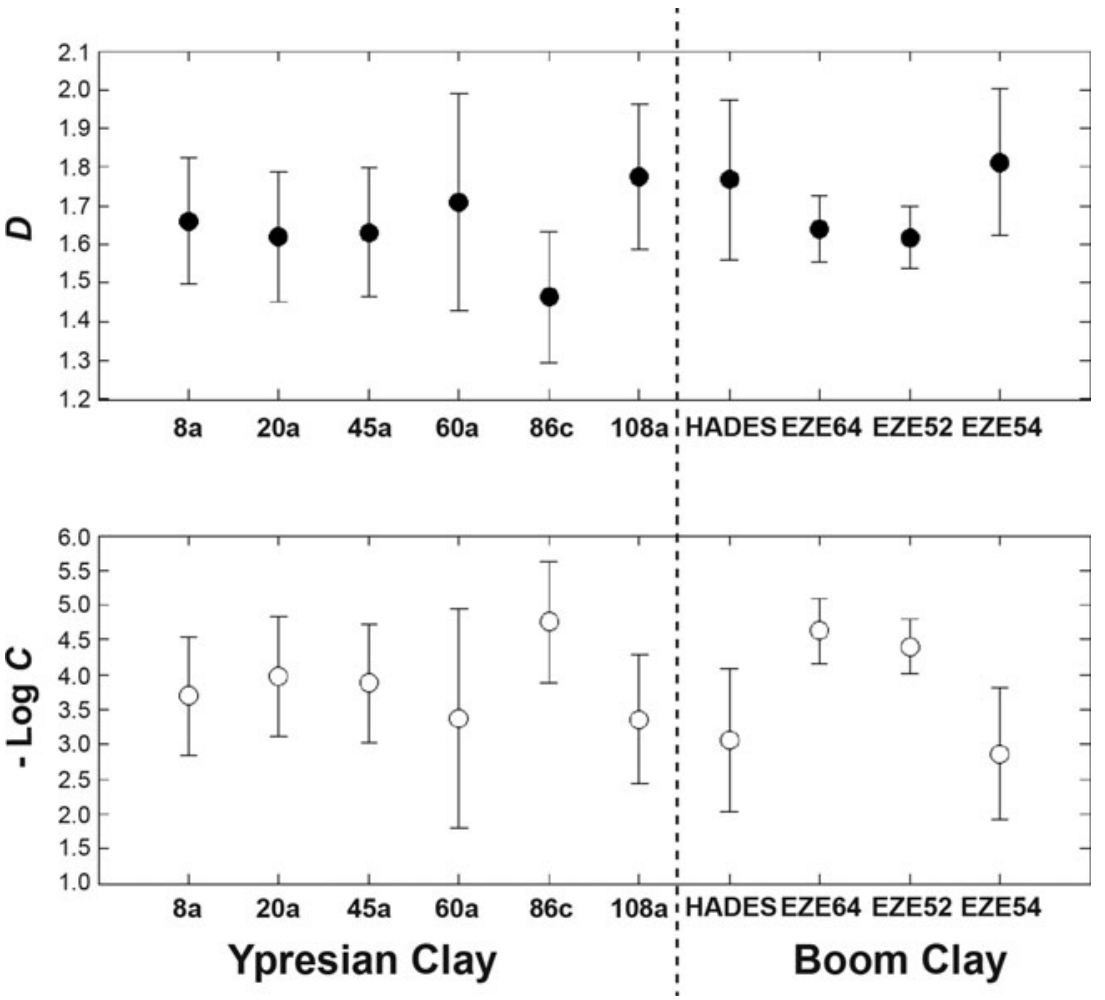

$<3 \times 10^{4} \mathrm{~nm}^{2}$ pore area (Fig. 8C). 'Type III' (inter-aggregate) pores in clay show very smooth, rounded pore boundaries (Figs 2, 5, 6 and 9) and can be very large, up to $\sim 5 \times 10^{9}$ $\mathrm{nm}^{2}$ pore area.

Based on these results, we infer that a higher content of NCMs causes a switch from a clay-matrix supported to a NCM grain-supported fabric. This leads to less compaction of the clay matrix and is also in agreement with the bedding parallel preferred orientation of the pores' longest axes in fine-grained, clay-rich Boom Clay (Hemes et al., 2013), which is absent in the Ypresian clay samples. The effect of NCMs controlling the pore space within and the microstructures of the clay matrix has also been reported in recent studies by Bobko and Ulm (2008), Hemes et al. (2013), Houben et al. (2014a), Keller et al. (2015) and Philipp et al. (submitted).

\section{Pore-space connectivity and relevance of the inter-aggregate pores in the Ypresian clays}

Although WMI reveals that all pores, including the pores within the clay matrix as well as larger inter-aggregates pores, are mutually connected at a maximum WM entry pressure of 156 $\mathrm{MPa}$, corresponding to accessible pore-throat diameters of $\sim 10$ $\mathrm{nm}, \mathrm{X}$-ray $\mu$-CT and focused ion beam milling (FIB)-SEM tomography are suggested to solve the question of whether large inter-aggregate pores are directly connected to each other or via much smaller pore throats within the clay matrix, as has been reported for a fine-grained, clay-rich Boom Clay sample, analysed by Hemes et al. (2015).

The origin of the large inter-aggregate pores still remains unclear, although they contribute significantly to the total observed porosity and may provide preferential pathways for fluid flow. We therefore suggest that the frequent occurrence of larger NCM grains within a sample's fabric favors an increase in permeability. We recommend checking this hypothesis by measuring permeability together with the grain-size distribution and mineralogy of a sample. The large inter-aggregate pores are systematically located at the interfaces between NCM grains and the clay matrix. Moreover, the size and occurrence of the large inter-aggregate pores correlates with the size and occurrence of the NCM grains within the same sample. We observed a correlation between the contribution of large inter-aggregate pores to the total BIB-SEM observed porosity (Cttp) and the NCM content of a sample, as measured by XRD (Table 1 and Fig. 15). Such a correlation has already been described and hypothesised for the Boom Clay (Hemes et al., 2013) and for the Opalinus Clay (Keller, 2015; Philipp et al., submitted). Another characteristic of the large inter-aggregate pores is their coating by a very low porous, thin clay layer (Fig. 9). The presence of these clay coatings at larger inter-aggregates pores suggests that they are not originating from drying or de-compaction damages, but are part of the preserved natural clay fabric. The origin of the clay coatings remains unknown to date. The clay coatings may correspond to secondary clay minerals, precipitated from the interaction of original clay minerals, quartz and/or feldspar grains 

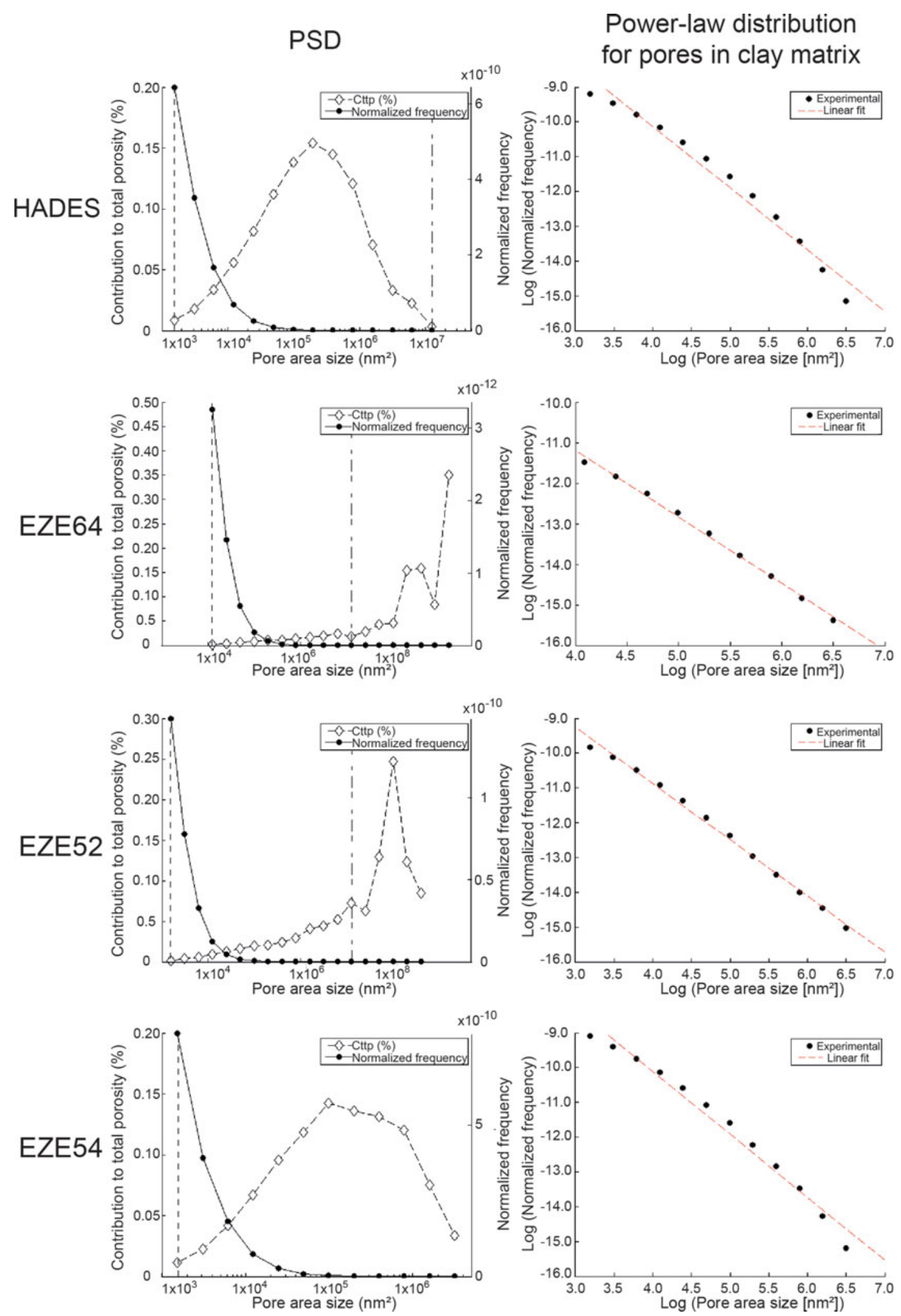

Fig. 14. Pore-area size distribution analyses on the Boom Clay samples from the Mol-1 borehole; data reworked from Hemes et al. (2013). Left: Normalised pore-size frequencies and contributions to total segmented porosities (Cttp (\%)). Right: Power-law distributions of pore-area sizes, within the clay matrix only. 
Fig. 15. Contribution of largest inter-aggregate pores $\left(>1 \times 10^{7} \mathrm{~nm}^{2}\right)$ to the total BIB-SEM observed porosity (\%), as a function of NCM content (dry wt\%) for Ypresian clay samples from this contribution, as well as the Boom Clay samples, analysed by Hemes et al. (2013).

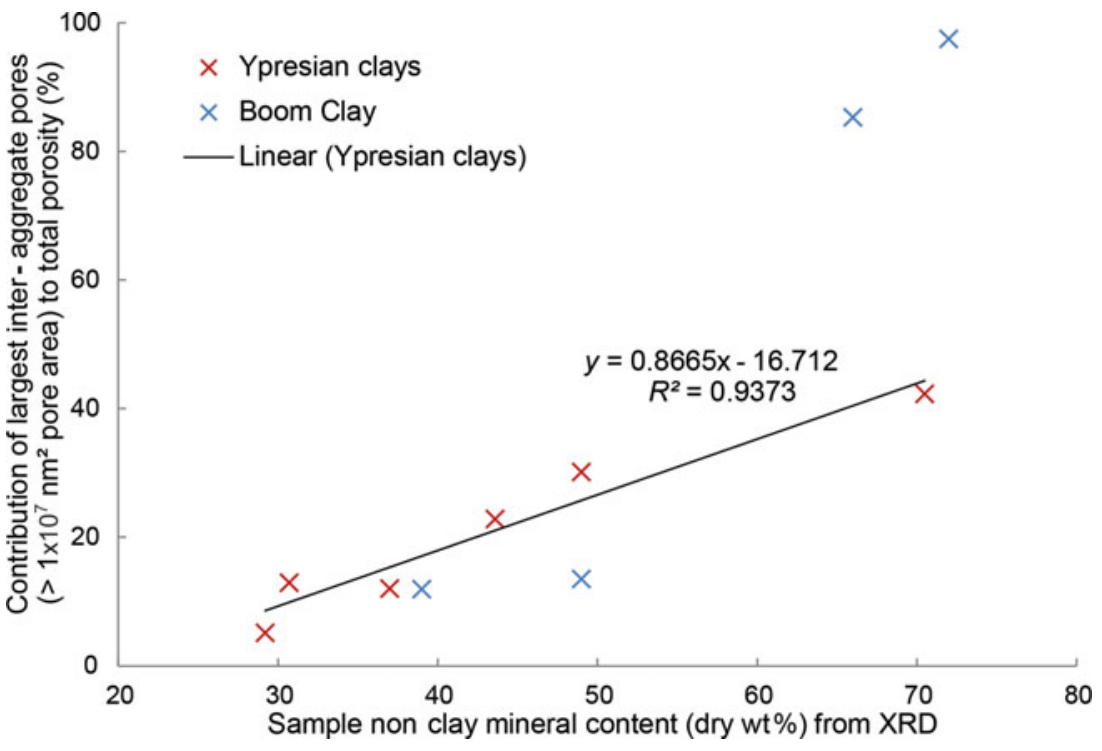

with non-equilibrated pore waters. Since clay coatings are not observed within the clay matrix, we suggest that large interaggregate pores are directly connected to each other, possibly forming the main pathway for fluid flow and transport within a sample.

\section{Conclusions}

BIB-SEM microstructural and in particular porosity analyses on six Ypresian clay samples from the ON-Kallo-1 borehole, within representative elementary areas (REAs) of BIB cross-sections, show microstructures and pore-space morphologies comparable to the Boom Clay (Hemes et al., 2013) for the fine-grained Ypresian clay samples analysed. However, different microstructural arrangements were observed for the more coarse-grained YPRC samples: (1) grain- and pore-area sizes as well as porosity distributions of the coarse-grained, NCM-rich samples are shifted towards larger values and (2) no bedding parallel alignment of the clay minerals was observed, possibly prevented by the higher NCM contents and larger grain sizes. Large inter-aggregate pores contribute significantly to the total BIB-SEM observed porosities, with their contributions to the total resolved porosity increasing linearly with increasing sample grain size and NCM content. Moreover, the preferred occurrence of the largest interaggregate pores at NCM-clay matrix interfaces is thought to play a significant role once these large pores are directly connected to each other, controlling the overall pore-space connectivity and affecting the permeability of the material.

Pore-area size distributions within the clay matrix of the Ypresian clays follow power laws, with comparable power-law exponents $D$ and $\log C$ values to the Boom Clay (Hemes et al., 2013), suggesting similar microstructures and pore-space morphologies within the clay matrix of these samples.
WMI on an Ypresian clay sample shows a very high overall connectivity of the pore space, down to $10 \mathrm{~nm}$ pore-throat diameter, comparable to results found for the Boom Clay (Hemes et al., 2015).

\section{Acknowledgements}

We would like to thank ONDRAF/NIRAS for providing the samples, financial support and XRD data $\left(Q_{\text {mineral }}\right.$ Analysis and Consulting, Heverlee, Belgium).

\section{Supplementary material}

To view supplementary material for this article, please visit http://dx.doi.org/10.1017/njg.2016.16

\section{References}

Abell, A.B., Willis, K.L. \& Lange, D.A., 1999. Mercury intrusion porosimetry and image analysis of cement-based materials. Journal of Colloid and Interface Science 211: 39-44.

Aertsens, M., Maes, N., Moors, H. \& Lemmens, K., 2008a. Diffusion experiments with 32Si in Boom Clay, FoCa Clay and the M2 mixture. External Report of the Belgian Nuclear Research Centre, Mol, Belgium. SCK•CEN-ER-39 (Mol): $77 \mathrm{pp}$.

Aertsens, M., De Cannière, P., Lemmens, K., Maes, N. \& Moors, H., 2008b. Overview and consistency of migration experiments in clay. Physics and Chemistry of the Earth 33: 1019-1025.

Aertsens, M., Van Gompel, M., De Cannière, P., Maes, N. \& Dierckx, A., 2008c. Vertical distribution of $\mathrm{H} 14 \mathrm{CO} 3$ transport parameters in Boom Clay in the Mol-1 borehole (Mol, Belgium): Clays in Natural and Engineered Barriers for Radioactive Waste Confinement. External Report of the Belgian Nuclear 
Research Centre (Mol). SCK. Physics and Chemistry of the Earth, Parts A/B/C, 33, Supplement 1 33: 61-66.

Blunt, M.J., Bijeljic, B., Dong, H., Gharbi, O., Iglauer, S., Mostaghimi, P., Paluszny, A. \& Pentland, C., 2013. Pore-scale imaging and modelling. Advances in Water Resources 51: 197-216.

Bobko, C. \& Ulm, F.-J., 2008. The nano-mechanical morphology of shale. Mechanics of Materials 40: 318-337.

Cammaer, C., Cockaerts, G. \& Schiltz, M., 2009. Drilling and géological report onkallo-1, on-kallo-2, on-kallo-3. ONDRAF/NIRAS - Technical report Samsuffit R2009-01.

Darot, M. \& Reuschlé, T., 1999. Direct assessment of Wood's metal wettability on quartz. Pure and Applied Geophysics 155: 119-129.

Desbois, G., Urai, J.L. \& Kukla, P.A., 2009. Morphology of the pore space in claystones - evidence from BIB/FIB ion beam sectioning and cryo-SEM observations. eEarth 4: 15-22.

Desbois, G., Urai, J.L., Hemes, S., Brassinnes, S., De Craen, M. \& Sillen, X., 2014. Nanometer-scale pore fluid distribution and drying damage in preserved clay cores from Belgian clay formations inferred by BIB-cryo-SEM. Engineering Geology 179: 117-131.

Dvorkin, J., Derzhi, N., Diaz, E. \& Fang, Q., 2011. Relevance of computational rock physics. Geophysics 76: E141-E153.

ESRI Inc., 2011. ArcGIS 10.2.1 for Desktop.

Hemes, S., 2015. Nm-scale pore space characteristics of the Boom Clay (Mol-1 borehole) and the Ypresian clays (Kallo-1 borehole). Dissertation RheinischWestfälischen Technischen Hochschule (RWTH). Department of Structural Geology Tectonica and Geomechanics, Energy and Mineral Resources Group (Aachen): $222 \mathrm{pp}$.

Hemes, S., Desbois, G., Urai, J.L., De Craen, M., Honty, M., Craen, M. De \& Craen, D., 2013. Variations in the morphology of porosity in the Boom Clay Formation: insights from 2D high resolution BIB-SEM imaging and mercury injection porosimetry. Netherlands Journal of Geosciences 92: 275-300.

Hemes, S., Desbois, G., Urai, J.L., Schröppel, B. \& Schwarz, J.0., 2015. Multiscale characterization of porosity in Boom Clay (HADES-level, Mol, Belgium) using a combination of X-ray $\mu$-CT, 2D BIB-SEM and FIB-SEM tomography. Microporous and Mesoporous Materials 208: 1-20.

Hildenbrand, A., 2003. Fluid Transport Processes in Mudstones. Dissertation RWTH. Aachen University (Aachen): 137 pp.

Hildebrand, A. \& Urai, J.L., 2003. Investigation of the morphology of pore space in mudstones - first results. Marine and Petroleum Geology 20: 1185-1200.

Houben, M.E., Desbois, G. \& Urai, J.L., 2013. Pore morphology and distribution in the Shaly facies of Opalinus Clay (Mont Terri, Switzerland): Insights from representative 2D BIB-SEM investigations on $\mathrm{mm}$ to $\mathrm{nm}$ scale. Applied Clay Science 71: 82-97.

Houben, M.E., Desbois, G. \& Urai, J.L., 2014a. A comparative study of representative 2D microstructures in Shaly and Sandy facies of Opalinus Clay (Mont Terri, Switzerland) inferred form BIB-SEM and MIP methods. Marine and Petroleum Geology 49: 143-161.

Houben, M., Desbois, G., Urai, J.L., Winter, D.A.M., Drury, M.R. \& Schwarz, J.0., 2014b. Microstructure of the Shaly facies of Opalinus Clay on the mm-nm scale. In Fourth EAGE Shale Workshop Shales: What Do They Have in Common? Porto, Portugal: EAGE Workshop abstracts, p. 5.
Huysmans, M. \& Dassargues, A., 2006. Hydrogeological modeling of radionuclide transport in low permeability media: a comparison between Boom Clay and Ypresian Clay. Environmental Geology 50: 122-131.

Jackson, M.L., 1985. Soil chemical analysis - advanced course. Parallel Press, University of Wisconsin - Madison Libraries (Madison, WI).

Jones, L., 1949. Deuxième Nivellement Général. Répertoire des définitions et des altitudes des repères. réseau de premier ordre (mesures faites en 1947 et 1948). Institut Géographique Militaire. Service de Nivellement, 2, Allée du Cloitre (Brussels).

Kanit, T., Forest, S., Galliet, I., Mounoury, V., Jeulin, D., Kang, M.-S., Watabe, Y. \& Tsuchida, T., 2003. Determination of the size of the representative volume element for random composites: statistical and numerical approach. International Journal of Solids and Structures 40: 3647-3679.

Keller, L.M., 2015. On the representative elementary volumes of clay rocks at the mesoscale. Academic Journals, Open Access - Journal of Geology and Mining Research 7(6): 58-64.

Keller, L.M., Holzer, L., Schuetz, P. \& Gasser, P.H., 2013. Pore space relevant for gas permeability in 0palinus clay: Statistical analysis of homogeneity, percolation, and representative volume element. Journal of Geophysical Research: Solid Earth 118: 2799-2812.

Klaver, J., Desbois, G., Urai, J.L. \& Littke, R., 2012. BIB-SEM study of the pore space morphology in early mature Posidonia Shale from the Hils area, Germany. International Journal of Coal Geology 103: 12-25.

Klaver, J., Hemes, S., Houben, M.E., Desbois, G., Radi, Z. \& Urai, J.L., 2015a. The connectivity of pore space in mudstones: insights from high-pressure Wood's metal injection, BIB-SEM imaging, and mercury intrusion porosimetry. Geofluids 15(4): 577-591.

Klaver, J., Desbois, G., Littke, R. \& Urai, J.L., 2015b. BIB-SEM characterization of pore space morphology and distribution in postmature to overmature samples from the Haynesville and Bossier Shales. Marine and Petroleum Geology 59: 451-466.

Labat, S., 2011. Overview and Analysis of 30 Years Piezometric Observations in North-East Belgium (Mol): $69 \mathrm{pp}$.

Lexa, 0. (2010). PolyLX - the MATLABTM toolbox for quantitative analysis of microstructures (Version 2.1). Institute of Petrology and Structural Geology, Charles University (Prague): 66 pp.

Mohammad, W., 2009. The NIRAS-ONDRAF Kallo $1 \& 2$ boreholes. The Ypresian cored section: 254-410 m depth. Laboratory of Applied Geology \& Mineralogy of KULeuven (Leuven): 120pp.

Nguyen, X.P., Cui, Y.J., Tang, A.M., Li, X.L. \& Wouters, L., 2014. Physical and microstructural impacts on the hydro-mechanical behaviour of Ypresian clays. Applied Clay Science 102: 172-185.

ONDRAF/NIRAS, 2001. SAFIR2 - Safety Assessment and Feasibility Interim Report 2 (NIROND 2001-06 E). ONDRAF/NIRAS (Brussels): 280 pp.

ONDRAF/NIRAS, 2011. Waste plan - for the long-term management of conditioned high-level and/or long-lived radioactive waste and overview of related issues (NIROND 2011-02E). ONDRAF/NIRAS (Brussels): 255 pp.

ONDRAF/NIRAS, 2013a. ONDRAF/NIRAS Research, Development and Demonstration (RD\&D) Plan for the geological disposal of high-level and/or long-lived radioactive waste including irradiated fuel if considered as waste. State-ofthe-art report as of December 2012. ONDRAF/NIRAS (Brussels): 413 pp. 
ONDRAF/NIRAS, 2013b. Proposal for sampling of Ypresian clays from the ON-Kallo 1 borehole in the framework of the characterisation of the pore network by RWTH Aachen. ONDRAF/NIRAS (Brussels): $13 \mathrm{pp}$.

Ortiz, L., Volckaert, G. \& Mallants, D., 2002. Gas generation and migration in Boom Clay, a potential host rock formation for nuclear waste storage. Engineering Geology 64: 287-296.

Philipp, T., Amann-Hildenbrand, A., Laurich, B., Desbois, G., Littke, R. \& Urai, J.L. (submitted). The effect of microstructural heterogeneity on pore size distribution and permeability in Opalinus Clay (Mont Terri, $\mathrm{CH}$ ): insights from an integrated study of laboratory fluid flow and pore morphology from BIBSEM images. Geological Society Special Publication.

$\boldsymbol{Q}_{\text {mineral }}$ Analysis and Consulting, 2014. Analysis Report. Aachen samples. Qmineral Analysis and Consulting (Belgium): 9 pp.

Renard, F., 2012. Microfracturation in rocks: from microtomography images to processes. The European Physical Journal Applied Physics 60(2): 24203.
Reynolds, R.C. \& Reynolds, R.C., 2012. Newmod II Software for modelling - X-Ray Diffraction of Mixed layer Clay Minerals Software For Research/Education: Quantitative Analysis/Mixed-Layer Clay Interpretation. http://www.newmod-for-clays.com/newmod-ii.html.

Scarlett, N.V.Y.N. \& Madsen, I.C.I., 2006. Quantification of phases with partial or no known crystal structures. Powder Diffraction 21: 278-284.

Steurbaut, E., 1998. High-resolution holostratigraphy of Middle Paleocene to Early Eocene strata in Belgium and adjacent areas. Palaeontographica Abt. A 247: 91-156.

Van Marcke, P., Laenen, B. \& Wouters, L., 2005. The Ypresian Clay as possible host rock for radioactive waste disposal: an evaluation (NIROND TR-2005-01 E). ONDRAF/NIRAS (Mol, Lille): $159 \mathrm{pp}$.

Washburn, E.W., 1921. The dynamics of capillary flow. Physical Review 17: 273283.

Winston, P.W. \& Donald, H., 1960. Saturated solutions for the control of humidity in biological research. Ecology 41: 232-237. 